\title{
Pseudomonas syringae Elicits Emission of the Terpenoid (E,E)-4,8,12-Trimethyl-1,3,7,11-Tridecatetraene in Arabidopsis Leaves Via Jasmonate Signaling and Expression of the Terpene Synthase TPS4
}

\author{
Elham Attaran, ${ }^{1}$ Michael Rostás, ${ }^{1}$ and Jürgen Zeier ${ }^{2}$ \\ 1 Julius-von-Sachs-Institute of Biological Sciences, University of Würzburg, Julius-von-Sachs-Platz 3, D-97082 Würzburg, \\ Germany; ${ }^{2}$ Department of Biology, Plant Biology Section, University of Fribourg, Route Albert Gockel 3, CH-1700 Fribourg, \\ Switzerland
}

Submitted 9 April 2008. Accepted 9 July 2008.

Volatile, low-molecular weight terpenoids have been implicated in plant defenses, but their direct role in resistance against microbial pathogens is not clearly defined. We have examined a possible role of terpenoid metabolism in the induced defense of Arabidopsis thaliana plants against leaf infection with the bacterial pathogen Pseudomonas syringae. Inoculation of plants with virulent or avirulent $P$. syringae strains induces the emission of the terpenoids $(E, E)-4,8,12$ trimethyl-1,3,7,11-tridecatetraene (TMTT), $\beta$-ionone and $\alpha$ farnesene. While the most abundant volatile, the $\mathrm{C}_{16}$-homoterpene TMTT, is produced relatively early in compatible and incompatible interactions, emission of both $\beta$-ionone and $\alpha$-farnesene only increases in later stages of the compatible interaction. Pathogen-induced synthesis of TMTT is controlled through jasmonic acid (JA)-dependent signaling but is independent of a functional salicylic acid (SA) pathway. We have identified Arabidopsis T-DNA insertion lines with defects in the terpene synthase gene TPS4, which is expressed in response to $P$. syringae inoculation. The tps4 knockout mutant completely lacks induced emission of TMTT but is capable of $\beta$-ionone and $\alpha$-farnesene production, demonstrating that TPS4 is specifically involved in TMTT formation. The tps4 plants display at least wild typelike resistance against $P$. syringae, indicating that TMTT per se does not protect against the bacterial pathogen in Arabidopsis leaves. Similarly, the ability to mount SA-dependent defenses and systemic acquired resistance (SAR) is barely affected in tps 4 , which excludes a signaling function of TMTT during SAR. Besides $P$. syringae challenge, intoxication of Arabidopsis leaves with copper sulfate, a treatment that strongly activates JA biosynthesis, triggers production of TMTT, $\beta$-ionone, and $\alpha$-farnesene. Taken together, our data suggest that induced TMTT production in Arabidopsis is a by-product of activated JA signaling, rather than an effective defense response that contributes to resistance against $P$. syringae.

Additional keywords: copper stress, disease resistance, terpene synthesis, terpene synthase4.

Corresponding author: J. Zeier; Telephone: +41 (0)26 300 8827; Fax: +41 (0)26 300 9740; E-mail: juergen.zeier@unifr.ch

* The $\boldsymbol{e}$-Xtra logo stands for "electronic extra" and indicates that Figures 1 and 5 appear in color online.
Upon attempted infection with bacterial, fungal, or viral pathogens, plants induce a whole array of defense reactions that collectively contribute to counteract microbial invasion. Induced resistance responses often include cell-wall reinforcements, production of reactive oxygen species (ROS), the hypersensitive cell death response (HR), accumulation of antimicrobial pathogenesis-related (PR) proteins, synthesis of defense metabolites of lower molecular weight, and establishment of a primed state to allow a faster and more effective reaction towards subsequent pathogen encounter (Conrath et al. 2002; Dangl and Jones 2001).

In the model plant Arabidopsis thaliana, several metabolic pathways are activated in response to microbial pathogens to yield low-molecular weight defense substances. The oxylipin pathway produces jasmonic acid (JA), 12-oxophytodienic acid (OPDA), and phytoprostanes, which either act as signaling intermediates that trigger expression of specific sets of PR and other defense genes or mediate detoxification responses following stress exposure (Farmer et al. 2003; Mueller et al. 2008). Activation of the general phenylpropanoid pathway via phenylalanine ammonia lyase can lead to the synthesis of lignin precursors, which bear direct antimicrobial activity and, via oxidative polymerization to lignin-like phenolics, are thought to contribute to cell-wall reinforcements at infection sites (Lee et al. 2001; Mishina and Zeier 2007a). A related pathway yields pathogen-induced accumulation of the $\mathrm{C} 6 \mathrm{C} 1$ phenolic salicylic acid (SA) and its derivatives via isochorismate synthase (Wildermuth et al. 2001). SA is a central defense signal ensuring basal and specific disease resistance towards many biotrophic and hemibiotrophic pathogens (Glazebrook 2005), and its accumulation is indispensable for the establishment of systemic acquired resistance (SAR) (Métraux 2002). SAR develops after a localized leaf contact with pathogenic or nonpathogenic microbes and provides broad-spectrum disease resistance against subsequent infections (Durrant and Dong 2004; Mishina and Zeier 2007b). In Arabidopsis leaf tissue facing attempted infection with biotrophic or necrotrophic pathogens, the tryptophan-associated branch of secondary metabolism is activated to yield the indole alkaloid camalexin (Glawischnig 2007). Camalexin is the characteristic phytoalexin of Arabidopsis and other crucifers that accumulates to high levels only in infected tissue and bears in vitro antimicrobial activity. In planta, it contributes to restrict leaf invasion by several necrotrophic but not biotrophic pathogens (Thomma et al. 1999; Zhou et al. 1999). Generally, 
phytoalexins are a chemically heterogeneous group of nonpolar metabolites of lower molecular weight, which, depending on the plant species, can be derived from general phenylpropanoid, isoflavonoid, alkaloid, or terpenoid metabolism (Kuć 1995).

Chemical plant responses to microbial attack also include the induced emission of volatile organic compounds (VOC). For instance, emission of antimicrobial "green leaf volatiles" (GLV), which are $\mathrm{C}_{6}$ aldehydes, alcohols, and their esters derived from the oxylipin pathway increases during bacterial infection in bean plants (Croft et al. 1993). Plant GLV release can prime neighboring plants to react more rapidly upon insect herbivore attack (Engelberth et al. 2004). In tobacco and Arabidopsis leaves, volatile methyl salicylate (MeSA) is produced via methylation of SA (Lee et al. 1995; Koo et al. 2007). MeSA has been implicated in both interplant communication as well as intraplant long-distance signaling culminating in increased whole-plant resistance against viral pathogens in tobacco (Park et al. 2007; Shulaev et al. 1997).

Terpenoids represent a major group of plant volatile compounds. The basic pathway of terpenoid biosynthesis involves the formation of the $\mathrm{C}_{5}$ precursor units isopentenyl diphosphate and dimethylallyl diphosphate through either the plastidlocalized methylerythritol phosphate or the cytosolic mevalonate pathway. Prenyltransferases catalyze the condensation of these $\mathrm{C}_{5}$ precursors to yield $\mathrm{C}_{10}, \mathrm{C}_{15}$, or $\mathrm{C}_{20}$ prenyl diphosphates, which are converted to monoterpenes, sesquiterpenes, and diterpenes, respectively, by terpene synthases (TPS) (Tholl 2006). The primary terpene products can be further modified through oxidation, C-C-cleavage, and acylation reactions that yield terpenoids with altered physicochemical properties. The vapor pressure of the majority of terpenoids containing 5 to 20 carbon atoms is high enough to allow significant plant emission into the air (Dudareva et al. 2004). Upon feeding or egg deposition by herbivorous insects, vegetative plant tissue often produces and emits increased amounts of volatile terpenoids within hours (Turlings 1998; Wegener et al. 2001). Herbivoreinduced terpenoids may function in indirect plant defense by attracting natural enemies of the herbivore or in direct defense against insects through repellent or toxic properties (Aharoni et al. 2003; Kessler and Baldwin 2001; van Poecke and Dicke 2004).

The role of terpenoids in defense against pathogenic microbes is less well understood. Tobacco plants challenged with Pseudomonas syringae bacteria increase the production of various VOC, including the monoterpenes (E)- $\beta$-ocimene and linalool and the sesquiterpenes caryophyllene, $\beta$-elemene, and $\alpha$-farnesene (Huang et al. 2003). Pathogen-induced terpenoids might function as typical phytoalexins, because many of those compounds possess direct antimicrobial properties (Soković et al. 2006). Alternatively, they could participate in defense signaling. A recent study reporting that the monoterpene allo-ocimene induces resistance responses and primes defense reactions against the fungal pathogen Botrytis cinerea supports this view (Kishimoto et al. 2006). Deductions about the function of terpenoids in defense and resistance against microbial pathogens, however, either result from in vitro studies or from experiments in which plant responses have been triggered by external application of terpenoid compounds in nonphysiological amounts. Direct genetic evidence for a possible defensive role of terpenoids actually produced in planta is still missing.

In the present study, we have examined a possible involvement of terpenoids in inducible defense responses of the model plant Arabidopsis thaliana towards avirulent and virulent $P$ seudomonas syringae strains. We first show that emission of the $\mathrm{C}_{16}$-homoterpene (E,E)-4,8,12-trimethyl-1,3,7,11-tridecatetraene (TMTT) is induced after inoculation with incompatible and compatible $P$. syringae strains. Induced TMTT production proceeds via upregulation of the TPS gene TPS4 and is controlled through jasmonate signaling, because tps4 T-DNA knockout plants as well as JA-pathway mutants either completely lack or display significantly reduced TMTT emission after pathogen contact. The use of tps 4 mutant plants devoid in TMTT production allowed us, for the first time, to assess the role of a terpenoid in defense and disease resistance under physiological conditions. We provide evidence that the failure to mount TMTT synthesis in tps 4 mutants does not critically affect local resistance or SAR, indicating that $P$. syringae-induced TMTT formation is not a decisive event for disease resistance towards the bacterial pathogen in Arabidopsis.

\section{RESULTS}

\section{Arabidopsis terpenoid volatiles produced in response to $P$. syringae inoculation.}

Leaf inoculation of Arabidopsis accession Col-0 with the compatible bacterial strain Pseudomonas syringae pv. maculicola ES4326 results in rapid bacterial multiplication in the leaf apoplast and development of yellowish, water-soaked disease lesions spreading in infected leaves (Mishina and Zeier 2007b). In comparison, ES4326 avrRpm1, a P. syringae pv. maculicola ES4326 strain expressing the AvrRpm1 avirulence protein, induces a HR at inoculation sites that restricts bacterial multiplication to a significant degree (Delledonne et al. 1998). The array of Arabidopsis defense reactions initiated in response to ES4326 or ES4326 avrRpm1 is well-studied and comprises accumulation of the defense metabolites SA, $\mathrm{JA}$, and camalexin, as well as increased expression of various defense-related proteins. Induction of these defense reactions during the early interaction period generally occurs in a more pronounced manner in response to avirulent ES4326 avrRpm1 than in response to virulent ES4326 (Mishina et al. in press).

We investigated whether induced production of VOC in inoculated Arabidopsis leaves would be part of the plant defense arsenal against $P$. syringae attack. Pathogen-inoculated or control-infiltrated plants were therefore placed in airtight glass chambers, and whole-plant emission of volatile compounds was determined through collection on a trapping filter and subsequent analysis of filter eluates by gas chromatography-mass spectrometry (Rostás et al. 2006). Compared with $\mathrm{MgCl}_{2}$-infiltrated control plants, Col- 0 plants inoculated with ES4326 avrRpm1 emitted strongly elevated levels of MeSA and a substance at higher retention times with two dominant masses in its mass spectrum at $\mathrm{m} / \mathrm{z}=69$ and $\mathrm{m} / \mathrm{z}=81$ (Fig. $1 \mathrm{~A}$ and B). Comparison of the mass spectrum with those of the National Institute of Standards and Technology (NIST 98) reference library, interpretation of mass spectral fragmentation patterns and coinjection with a standard substance identified the compound as (E,E)-4,8,12-trimethyl-1,3,7,11-tridecatetraene (TMTT) (Fig. 1C), a $\mathrm{C}_{16}$-homoterpene produced by many plants in response to herbivory (Ament et al. 2006; Hopke et al. 1994; Paré and Tumlinson 1997). A detailed timecourse analysis revealed that TMTT is not produced in Col-0 leaves before $10 \mathrm{~h}$ postinoculation (hpi) with either avirulent or virulent $P$. syringae (Fig. 2A). Its emission was strongly increased between 10 and 24 hpi upon treatment with both ES4326 avrRpm1 and ES4326, and its production was maintained for two or at least three days in the compatible and incompatible interaction, respectively. Basal levels of emitted TMTT in untreated plants were virtually absent, and control infiltrations with $\mathrm{MgCl}_{2}$ only caused traces of TMTT emission. Besides TMTT, two other terpenoid volatiles emitted in low amounts from Arabidopsis leaves, $\beta$-ionone and $\alpha$-farnesene, were iden- 

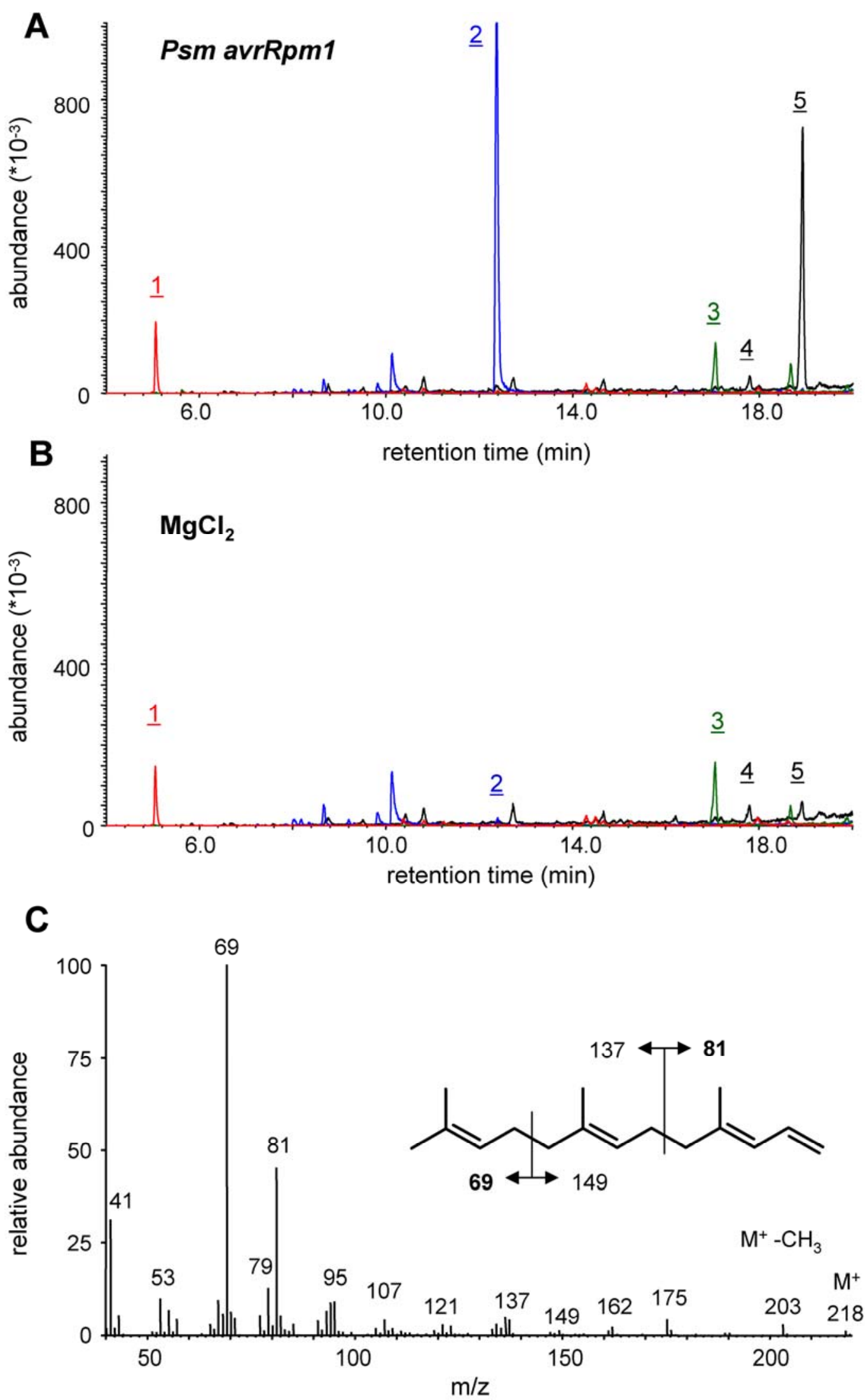

Fig. 1. Gas chromatography-mass spectrometry analyses of volatiles emitted from Pseudomonas syringae-treated Arabidopsis plants. A and B, Selected ion chromatograms (m/z 114, red; m/z 120, blue; m/z 177 green; m/z 81, black) illustrating profiles of released Arabidopsis volatiles. A, Volatiles were collected for $24 \mathrm{~h}$ after inoculation of leaves with $P$. syringae pv. maculicola avrRpml (optical density $=0.01$ ), and $\mathbf{B}$, after infiltration with $10 \mathrm{mM} \mathrm{MgCl}$ as a control treatment. The compounds represented by the peaks in the different ion chromatograms were identified as follows: $1, \mathrm{n}$-octane (internal standard; m/z 114); 2, methyl salicylate (m/z 120); 3, $\beta$-ionone (m/z = 177); 4, $\alpha$-farnesene ( $/ \mathrm{z}=81)$; and 5, (E,E)-4,8,12-trimethyl-1,3,7,11-tridecatetraene (TMTT) $(\mathrm{m} / \mathrm{z} 81)$. C, Mass spectrum of substance 5 (identified as TMTT), structural formula of TMTT, and proposed mass spectral fragmentation patterns. 
A

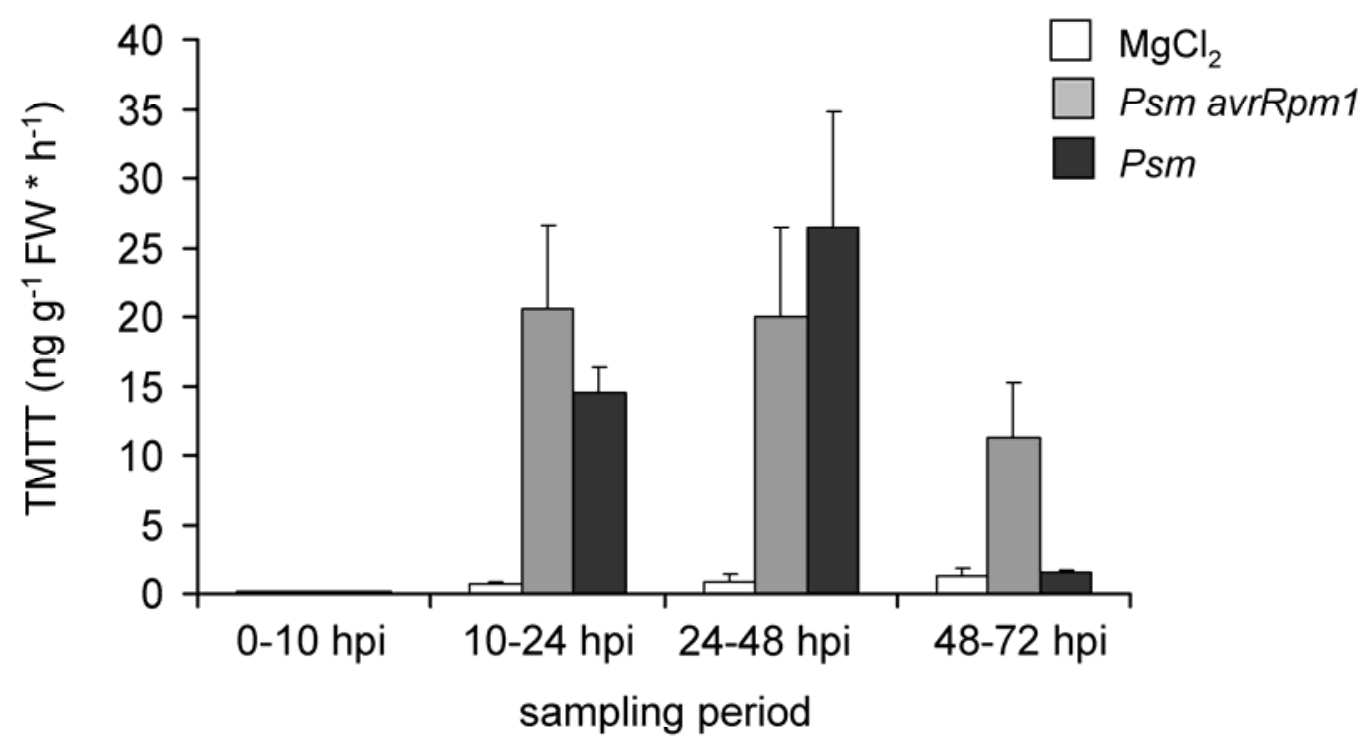

B
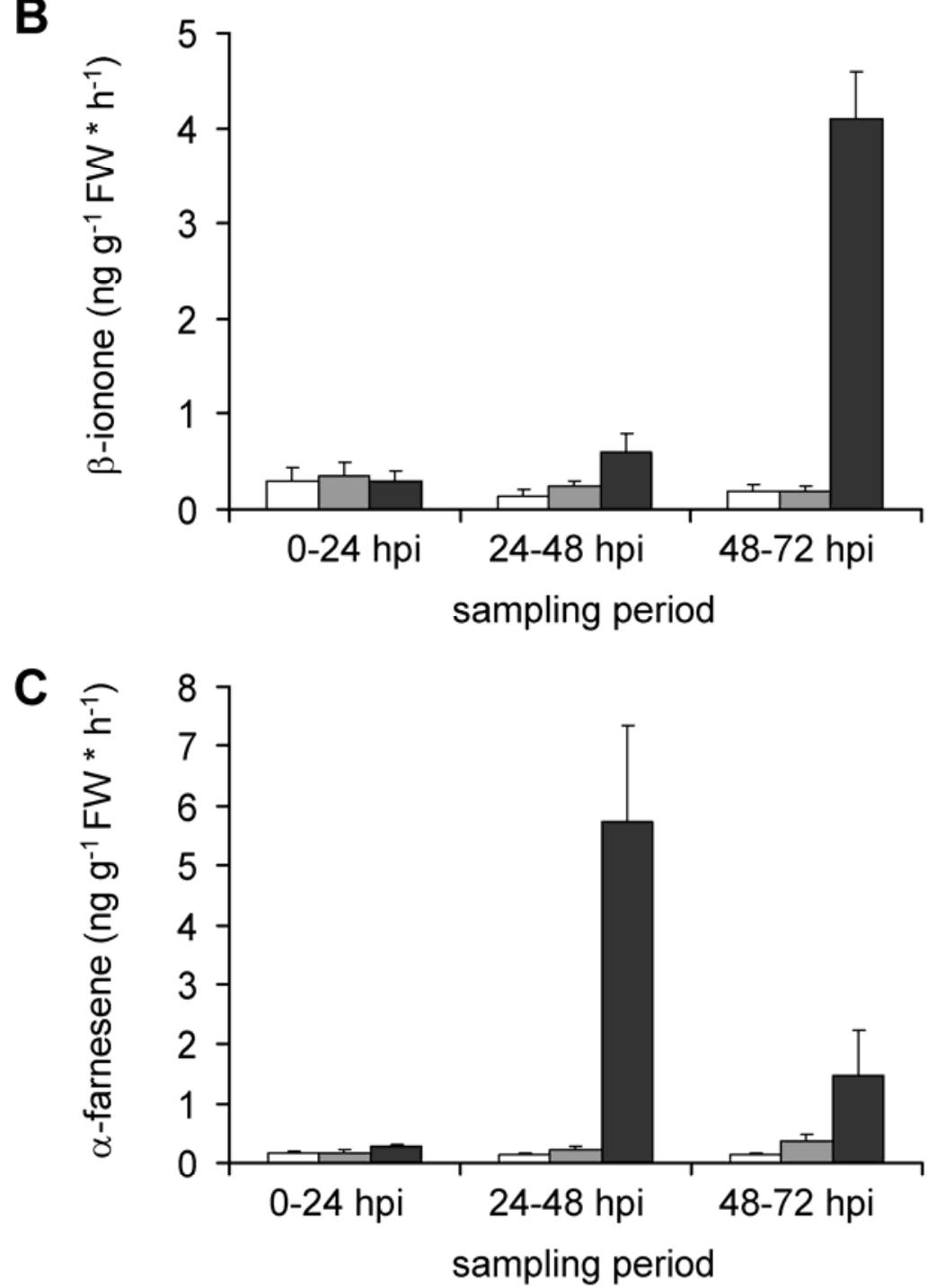

Fig. 2. Timecourse of terpenoid emission from Arabidopsis Col-0 plants inoculated with Pseudomonas syringae pv. maculicola avrRpm1 (Psm avrRpm1) (incompatible interaction; light gray bars), $P$. syringae pv. maculicola ( $P s m)$ (compatible interaction; dark gray bars), or infiltrated with 10 mM $\mathrm{MgCl}_{2}$ (control; white bars). Bars represent mean emission values ( \pm standard deviation) from three independent plants. The time periods in which volatiles have been collected are indicated in hours postinoculation (hpi). Values are given in nanograms of volatile substance per gram of fresh weight (FW) per h. A, (E,E)4,8,12-trimethyl-1,3,7,11-tridecatetraene emission, $\mathbf{B}, \beta$-ionone emission, and $\mathbf{C}, \alpha$-farnesene emission. 
tified (Fig. 1A). Leaf emission of either substance did not increase after treatments with both $\mathrm{MgCl}_{2}$ and $\mathrm{ES} 4326$ avrRpm1 but was significantly elevated during later periods of the compatible Col-0-ES4326 interaction (Fig. 2B and C).

Emission of typical GLV such as (Z)-3-hexen-1-ol or hexanal was virtually absent in $\mathrm{MgCl}_{2^{-}}$and $P$. syringae-treated Col-0 plants, except for interactions with the compatible ES4326 strain during the sampling period between 24 and $48 \mathrm{hpi}$, when traces of (Z)-3-hexen-1-ol could be detected in the volatile blend. Similarly, volatile glucosinolate degradation products such as 4-methylthiobutyl-isothiocyanate or 5-methylthiopentane-nitril were not detected after $\mathrm{MgCl}_{2}$ or $P$. syringae infiltrations. Above mentioned GLV and mustard oils, however, were emitted to significant amounts from artificially damaged Col-0 leaves (data not shown).

\section{Regulation of $\boldsymbol{P}$. syringae-triggered TMTT production.}

Many plant responses to pathogens are either mediated by SA- or JA-induced signaling pathways (Halim et al. 2006; Reymond and Farmer 1998). Activation of terpenoid biosynthesis in response to herbivore attack has been reported in several plant species to depend on JA signaling (Ament et al. 2004; Arimura et al. 2008; Mercke et al. 2004). Using mutant lines that are either blocked in JA or SA biosynthesis or impaired in the respective signaling pathways, we tested whether microbial induction of TMTT synthesis in Arabidopsis would require JA- or SA-dependent signaling. In contrast to their corresponding wild-type background lines Col-0 and Ws, $P$. syringae-induced TMTT emission was virtually absent in $d d e 2$ and opr3 mutant plants, which are defective in the allene oxide synthase and 12-oxophytodienoic acid reductase JA biosyn-

\section{A}
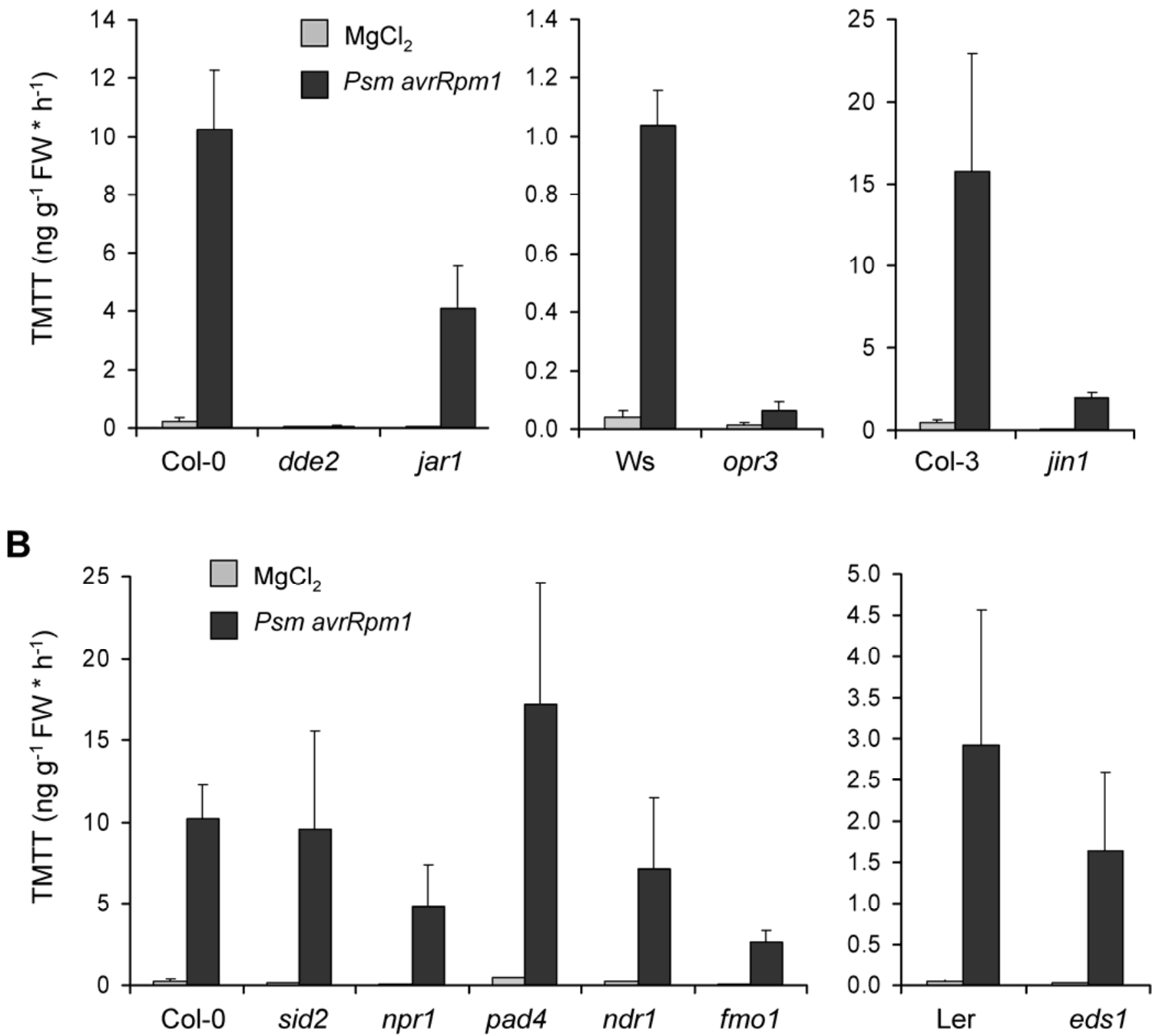

Fig. 3. Pseudomonas syringae-induced (E,E)-4,8,12-trimethyl-1,3,7,11-tridecatetraene (TMTT) emission in Arabidopsis defense mutants. TMTT emission from plants inoculated with P. syringae pv. maculicola avrRpml (dark bars) or infiltrated with $10 \mathrm{mM} \mathrm{MgCl}$ (control, light bars). Volatiles were collected from 0 to $24 \mathrm{~h}$ postinoculation. Bars represent mean emission values ( \pm standard deviation) from three independent plants. A, Jasmonic-acid pathway mutants. B, Mutants directly or indirectly related to salicylic acid signaling. 
thesis genes (Stintzi and Browse 2000; von Malek et al. 2002), respectively (Fig. 3A). Elicitation of TMTT production by avirulent $P$. syringae thus strongly depends on the plants capability to synthesize JA. Downstream components of JA signaling involve jasmonate-amino acid synthetase (JAR1) and the MYC transcription factor AtMYC2 (JIN1) (Lorenzo et al. 2004; Staswick et al. 2004). In both jarl and jinl mutant lines, $P$. syringae-induced TMTT production was significantly lower than in the respective wild-type plants Col-0 and Col-3, albeit its synthesis was not fully suppressed (Fig. 3A). This indicates that both JIN1 and JAR1 contribute to the JA-mediated control of pathogen-elicited TMTT synthesis.

In contrast to JA production, SA accumulation is not required for ES4326 avrRpm1 elicitation of TMTT synthesis in Arabidopsis, because the pathogen provoked wild-type-like TMTT emission in the SA biosynthesis mutant sid2 (Fig. 3B) (Nawrath and Métraux 1999). Moreover the SA pathwayrelated defense components PHYTOALEXIN-DEFICIENT4 (PAD4) (Glazebrook et al. 1997), NON-RACE SPECIFIC DISEASE RESISTANCE1 (NDR1) (Century et al. 1995), and ENHANCED DISEASE SUSCEPTIBILITY1 (EDS1) (Parker et al. 1996) are not involved in $P$. syringae-induced TMTT synthesis, because respective mutant plants exhibited induced production of the homoterpene. This was also true for the SAinsensitive mutant nonexpressor of PR-1 (nprl) (Cao et al. 1994) and the SAR-defective defense mutant flavin-dependent monooxygenasel (fmol) (Mishina and Zeier 2006), although induced TMTT emission was lower in the latter two lines than in wild-type plants (Fig. 3B). Taken together, these data indicate that SA-related signaling pathways are not essential for pathogen-induced TMTT synthesis. Natural variation, on the other hand, has a stronger impact on the amount of produced TMTT, because its emission by the three Arabidopsis accessions that were used differed in relative levels of emitted TMTT $(\mathrm{Col}>$ Ler $>$ Ws; Fig. 3$)$.

\section{Arabidopsis TPS4 is involved in induced TMTT synthesis.}

In Arabidopsis, 32 functional TPS genes exist that are thought to mediate synthesis of terpenes out of prenyl diphosphate precursors (Aubourg et al. 2002). Microarray analyses indicate that four of these genes-TPS2, TPS3, TPS4 and TPS10 - are upregulated in Arabidopsis leaves upon $P$. syringae pv. tomato inoculation (Fig. 4A). Thereof, expression of TPS4 (At1g61120) is induced most prominently by both avirulent and virulent $P$. syringae pv. tomato strains. Gel-blot analyses revealed that Col-0 leaves inoculated with the incompatible ES4326 avrRpm1 strain induce expression of TPS4 from at least $10 \mathrm{hpi}$ onward and that expression of the gene in response to the compatible ES4326 strain was slower but reached a high value at $24 \mathrm{hpi}$ (Fig. 4B). Taking these expression characteristics and our TMTT emission data as a basis for our rationale, we hypothesized that TPS4 might encode a TPS that is involved in TMTT biosynthesis. To directly test the presumed function of TPS4 for TMTT production in planta, we intended to identify and characterize Arabidopsis T-DNA insertion lines with a TPS4 knockout. The T-DNA Express Arabidopsis Gene Mapping Tool predicts several lines with putative disruptions of the TPS 4 coding region. When applying the polymerase chain reaction (PCR)-based protocol described by Alonso and associates (2003) to confirm the predicted insertions, we merely identified a single line, SALK_078187, that indeed harbors the T-DNA insert within the TPS4 coding region (Fig. 4C). Plants homozygous for the insert, from here on designated as tps4, completely lack basal or pathogeninduced expression of the TPS4 gene (Fig. 4D). When comparing volatile emissions from ES4326 avrRpm1-treated Col-0 and tps 4 plants, we obtained nearly identical profiles, except that the TMTT peak was totally absent in the tps 4 volatile blend (Fig. 5A through C). This confirmed our hypothesis that functional TPS4 is required for biosynthesis of TMTT in Arabidopsis. We additionally identified two Arabidopsis lines (tps10-1, SALK_108420 and tps10-2, SALK_041114) with inserts in the TPS10 gene (At2g24210), which is also upregulated in response to $P$. syringae. Emission profiles and TMTT production of both tps10 lines, however, were indistinguishable from those of Col-0, suggesting that TPS10 is not involved in the production of TMTT and other volatile terpenoids in Arabidopsis (Fig. 5C).

\section{Is there a defensive role for TMTT against $P$. syringae attack?}

The tps 4 mutant blocked in TMTT biosynthesis represented an excellent tool to study the functional relevance of induced terpenoid production in the Arabidopsis- $P$. syringae interaction. We reasoned that TMTT might function as a phytoalexin that directly contributes to restricting bacterial growth in inoculated leaf tissue. In this case, tps 4 mutants should exhibit decreased resistance towards $P$. syringae as compared with wildtype plants. However, when assessing bacterial growth in leaves inoculated with either ES4326 avrRpm1 or with ES4326, tps4 did not allow the bacteria to multiply more vigorously in extracellular spaces than did Col-0. Instead, specific resistance to ES4326 avrRpm1 and basal resistance to ES4326 were similar in tps 4 and Col-0 plants, with a slight tendency to an even higher degree of resistance toward both strains for tps4 (Fig. 6). These results clearly exclude a function for TMTT as a phytoalexin that is effective against the eliciting $P$. syringae pathogen.

Still, TMTT might play alternative roles in defense signaling, thus influencing or priming other defense reactions. Therefore, we tested whether differences existed in Col-0 and tps 4 with regard to the induction of typical defense responses at sites of ES4326 avrRpm1 inoculation. Accumulation of SA and JA as well as induced expression of the PR gene $P R-1$, however, were virtually identical in Col- 0 and tps 4 mutants, demonstrating that TMTT production has no impact on these responses (Fig. 7A, B, and D). By contrast, we observed a reduced accumulation of the phytoalexin camalexin in tps 4 as compared with Col-0 (Fig. 7C). This difference could principally be based on positive cross-talk between TMTT formation and camalexin biosynthesis. Alternatively, it might be a simple consequence of reduced bacterial multiplication in tps 4 compared with Col0 (Fig. 6A), resulting in an overall lower stimulatory activity towards camalexin production.

To clarify this point, we intended to examine plant responses toward a more constant abiotic stimulus possessing both camalexin- and TMTT-eliciting activity. Because heavy metal ions like $\mathrm{Cu}^{2+}$ are known to trigger camalexin biosynthesis in Arabidopsis (Pedras and Adio 2008), we treated leaves with 10 $\mathrm{mM} \mathrm{CuSO}_{4}$ and comparatively analyzed small metabolite content in and VOC emission from Col-0 and tps 4 plants. This leaf intoxication with $\mathrm{CuSO}_{4}$ indeed evoked simultaneous camalexin production and TMTT formation in Col-0 (Fig. 8A and E) and, further, lead to $\beta$-ionone and $\alpha$-farnesene emission. Remarkably, $\mathrm{CuSO}_{4}$ treatment induced the biosynthesis of volatile terpenoids similar in both quality and quantity to those induced by $P$. syringae inoculation (Figs. 8A through $\mathrm{C}$ and 2). The absence of TMTT emission in $\mathrm{CuSO}_{4}$-treated tps 4 mutant plants confirmed the requirement of functional TPS4 for TMTT biosynthesis (Fig. 8A). By contrast, emission of both $\beta$-ionone and $\alpha$-farnesene from tps 4 plants was induced to at least wild-type levels, indicating that TPS4 is not involved in the biosynthesis of either of those terpenes (Fig. 8B and C). The similarities between the $P$. syringae-induced and the $\mathrm{CuSO}_{4}$-triggered plant response were also evident when other 


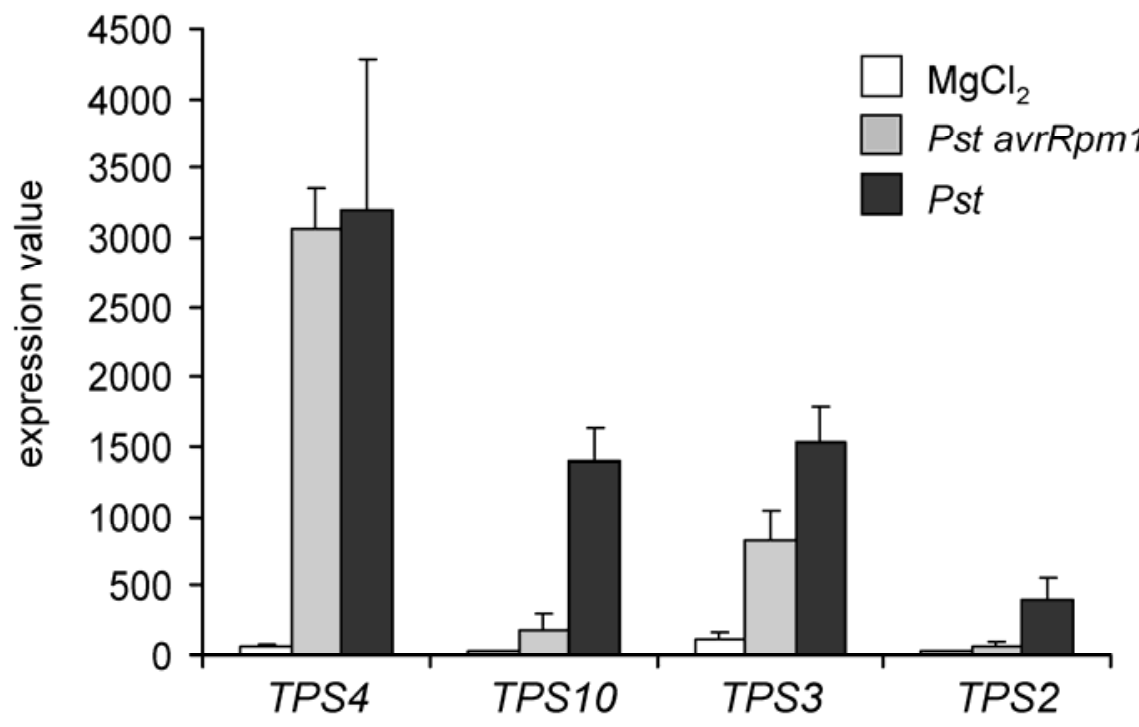

B
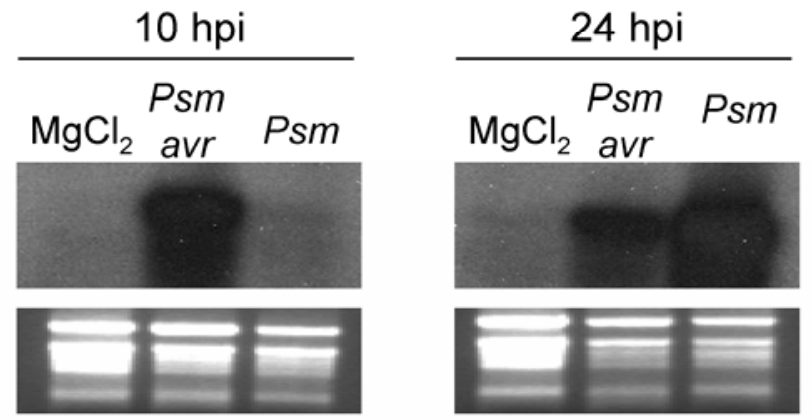

\section{TPS4}

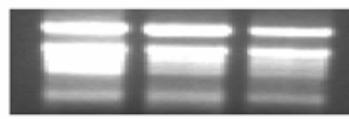

C

Col-0 tps4

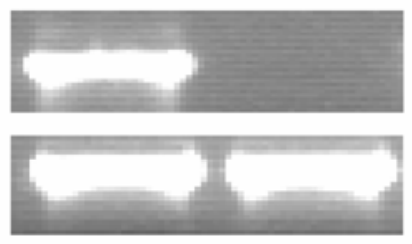

TPS4

\section{ACT2}

D

Col-0
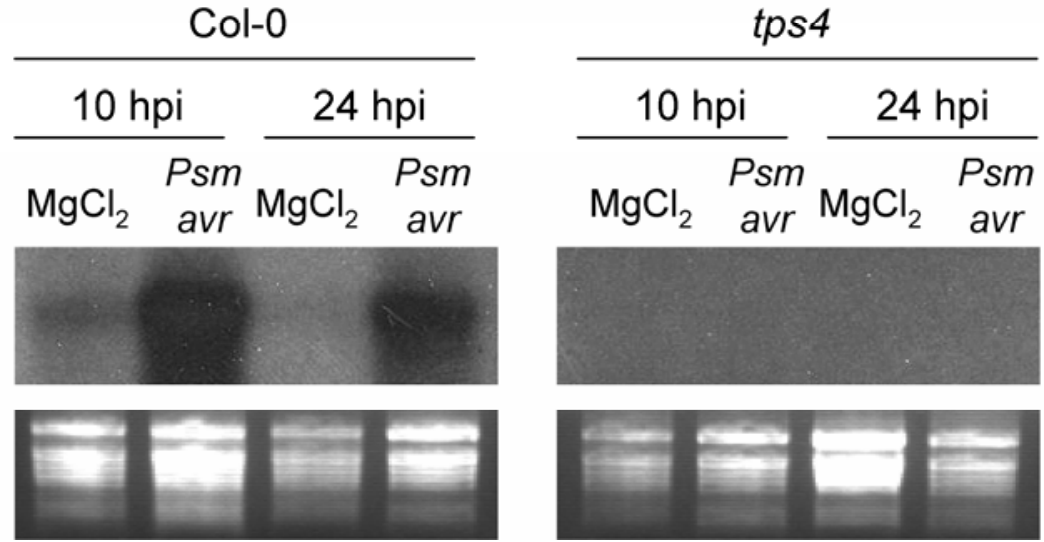

Fig. 4. Expression patterns of TPS4 and other terpene synthase (TPS) genes in Pseudomonas syringae-inoculated Arabidopsis leaves. A, Expression levels (24 h postinoculation [hpi]) of TPS genes in Col-0 leaves challenged with Pseudomonas syringae pv. tomato (Pst) according to microarray analyses (The Arabidopsis Information Resource 'TAIR-ME00331: Response to virulent, avirulent, type III secretion system deficient and nonhost bacteria'). Means ( \pm standard deviation) of Affymetrix expression values originating from three independent replicates are given. The data are normalized according to the Affymetrix MAS 5.0 scaling protocol. B, Expression of TPS4 in leaves inoculated with P. syringae pv. maculicola avrRpml (Psm avr) or P. syringae pv. maculicola (Psm), as assessed by Northern blot analysis. Control samples were infiltrated with $10 \mathrm{mM} \mathrm{MgCl}$. Leaf samples were taken at 10 and 24 hpi. C, Polymerase chain reaction analyses with genomic DNA from Col-0 or tps4 mutant (T-DNA insertion line SALK_026163) plants as templates, indicating a TDNA insert in the TPS4 coding region of $t p s 4$. The following gene-specific primers were used for TPS4 amplification: TPS4-forward, 5'-GCGTACGACAAG TATTTGCAG-3' and TPS4-reverse, 5'-AAGTTCACGG-CCTAATGCTTC-3'. The actin gene ACT2 was amplified as a positive control. D, Expression patterns of TPS4 in Col- 0 and tps 4 leaves infiltrated with $10 \mathrm{mM} \mathrm{MgCl}{ }_{2}$ or $P$. syringae pv. maculicola avrRpm1, as assessed by Northern blot analysis. Leaf samples are taken at 10 and 24 hpi. 
low-molecular weight metabolites were analyzed. Like $P$. syringae, $\mathrm{CuSO}_{4}$ evoked emission of MeSA as well as strong synthesis of camalexin, SA, and JA (Fig. 8D through G). Induced levels of all these defense-related metabolites were virtually identical in Col- 0 and tps 4 , which excludes the abovementioned possibility of cross-talk between camalexin and TMTT synthesis.

SAR involves the generation of one or more long-distance signals at sites of pathogen attack, signal translocation towards distant plant parts, and the initiation of defense responses in systemic tissue (Mishina et al. in press). To test whether TMTT production is required for the overall SAR process, we examined the capability of tps 4 mutant plants to mount defense responses and to enhance resistance at the systemic level. Therefore, three lower rosette leaves $\left(1^{\circ}\right.$ leaves) of a given plant were either infiltrated with $10 \mathrm{mM} \mathrm{MgCl}_{2}$ in a control treatment or inoculated with a suspension of ES4326 for biological induction of SAR. Three upper, previously untreated leaves $\left(2^{\circ}\right.$ leaves $)$ were collected 2 days later and were analyzed for SA content and PR gene expression or were subject to a subsequent ES4326 challenge. Systemic resistance was assessed by scoring bacterial growth in $2^{\circ}$ leaves 3 days after the challenge infection. We found that SA contents of $2^{\circ}$ leaves were considerably elevated in both Col-0 and tps 4 after ES4326 infection of $1^{\circ}$ leaves and that expression levels of the SAR gene $P R-1$ was increased in $2^{\circ}$ leaves of both lines after the $1^{\circ}$ ES4326-treatment (Fig. 9B and C). Although these systemic responses tended to be somewhat less pronounced in tps 4 than in Col-0, reduction of ES4326 growth in $2^{\circ}$ leaves upon $1^{\circ}$ leaf inoculation occurred to a similar degree in Col- 0 and tps 4 mutant plants (Fig. 9A). This indicates that SAR establishment in Arabidopsis is essentially independent of TMTT production.

\section{DISCUSSION}

We have analyzed the induced production of VOC in Arabidopsis plants that were challenged with incompatible and compatible $P$. syringae strains (Figs. 1 and 2). Induced synthesis of
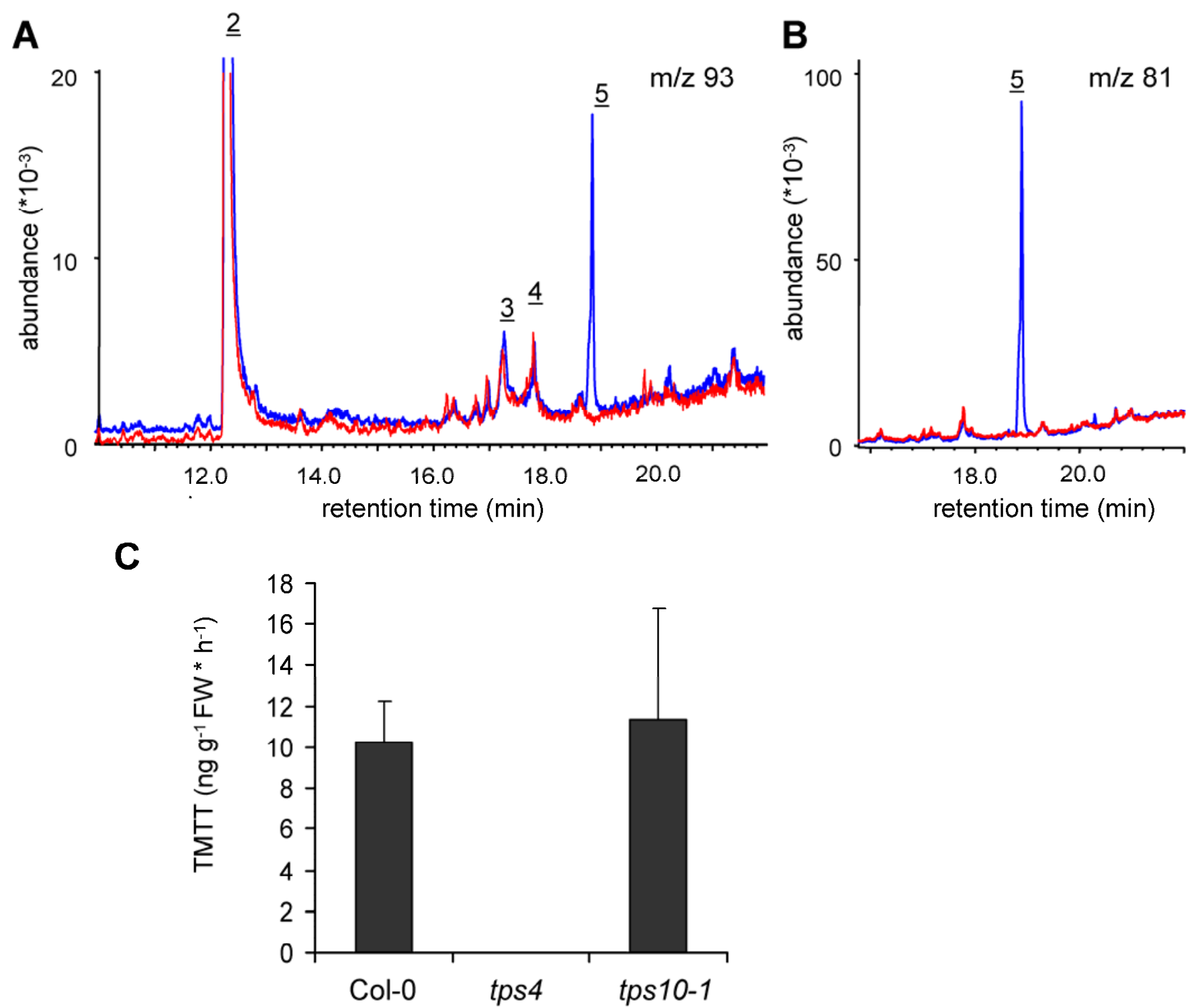

Fig. 5. Pseudomonas syringae-induced volatile and (E,E)-4,8,12-trimethyl-1,3,7,11-tridecatetraene (TMTT) emission from wild-type Col-0, tps4 mutant, and tps 10 mutant plants. A, Ion chromatograms at $\mathrm{m} / \mathrm{z} 93$ of volatile samples from Col-0 plants (blue) and tps 4 plants (red), simultaneously illustrating methyl salicylate (2), $\beta$-ionone (3), $\alpha$-farnesene (4), and TMTT (5) emission. B, Ion chromatograms at $\mathrm{m} / \mathrm{z} 81$ of Col-0 (blue) and tps4 (red) volatile samples more explicitly demonstrating the absence of TMTT in the tps 4 sample. C, Quantification of TMTT emitted from wild-type Col-0 plants, tps 4 mutant plants, and tps 10-1 mutant plants inoculated with $P$. syringae pv. maculicola avrRpm1. Volatiles were collected from 0 to $24 \mathrm{~h}$ postinoculation. Bars represent mean emission values ( \pm standard deviation) from three independent plants. The tps 10-2 mutant exhibited similar levels of emission to tps $10-1$ (data not shown). 
two major volatile substances, the phenylpropanoid MeSA and the $\mathrm{C}_{16}$-homoterpene TMTT, is part of the response repertoire of Arabidopsis against attack by avirulent ES4326 avrRpm1 and virulent ES4326. Later plant responses in compatible interactions of Arabidopsis with ES4326 comprise induced emission of the terpenoids $\beta$-ionone and $\alpha$-farnesene. Induced VOC production in response to $P$. syringae has been previously observed for tobacco (Huang et al. 2003). The volatiles produced by this plant species include MeSA, indole, and a broad spectrum of terpenoids consisting of $\beta$-ocimene, linalool, $\alpha$-farnesene, caryophyllene, and $\beta$-elemene as well as of two unidentified sesquiterpenes. Analogous to Arabidopsis, bacterial strains differing in their virulence properties elicit emission of distinct volatile blends from tobacco.

According to our results, Arabidopsis Col-0 leaves fail to provoke emission of typical green-leaf volatiles upon inoculation with avirulent ES4326 avrRpm1. Substantial amounts of the GLV (Z)-3-hexen-1-ol and (E)-2-hexenal, by contrast, are emitted from bean leaves after inoculation with incompatible $P$. syringae pv. phaseolicola. This and the fact that (Z)-3hexen-1-ol bears bactericidal activity at low concentrations suggest that GLV contribute to pathogen resistance in bean (Croft et al. 1992). Our emission data, however, argue against a comparable role of GLV in Arabidopsis defense towards $P$. syringae attack. This might be particularly true for the examined Col-0 accession, which, compared with other ecotypes, exhibits reduced expression and activity of hydroperoxide lyase and has consequently only a weak ability to produce GLV (Duan et al. 2005). Nevertheless, in contrast to pathogen infection, severe mechanical damage of Col-0 leaves gave rise to the emission of clearly detectable amounts of the GLV (Z)3-hexen-1-ol and hexanal in our experiments. Similarly, the lack of leaf emission of volatile mustard oils after $P$. syringae challenge indicates that the glucosinolate-myrosinase system, which is effective in Arabidopsis defense against insect herbivore attack (Barth and Jander 2006), is not an integral part of the defense arsenal operating against hemibiotrophic bacterial pathogens.

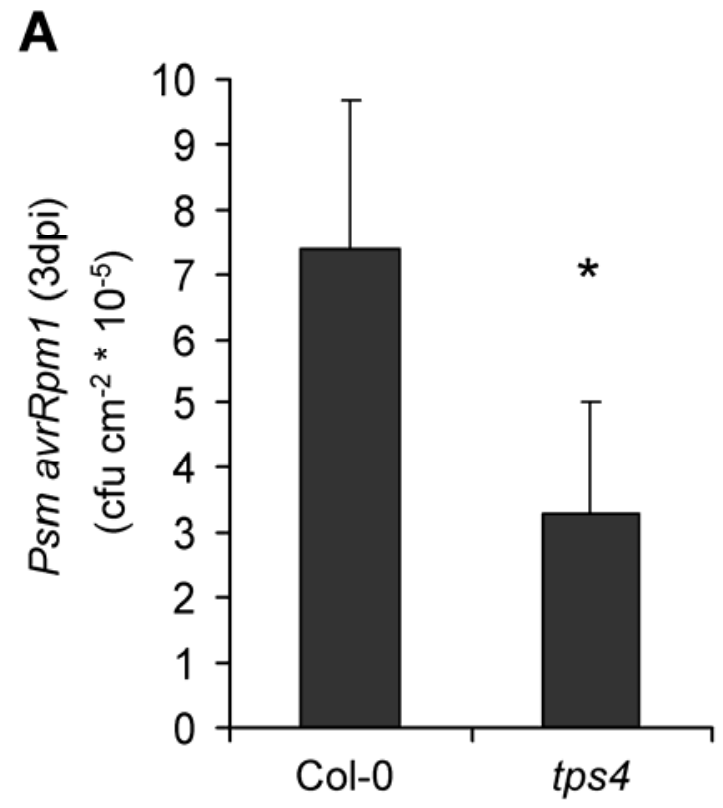

This study has focused particularly on the regulation of $P$. syringae-induced TMTT production in Arabidopsis and on its significance for defense and disease resistance against this microbial pathogen. Increased emission of TMTT as a plant response to biotic stress was first shown to occur in spider miteinfested lima bean and has since then been detected in many plant species attacked by herbivores (Ament et al. 2006; Hopke et al. 1994; Paré and Tumlinson 1997). Upon leaf feeding by Pieris rapae caterpillars and Plutella xylostella larvae, TMTT is also produced in Arabidopsis (Herde et al. 2008; van Poecke et al. 2001). The presence of TMTT in odors of lima bean positively influences the foraging behavior of natural enemies of spider mite herbivores feeding on this plant species, suggesting a signaling function for the homoterpene in indirect plant defense against herbivorous arthropods (De Boer et al. 2004). Moreover, TMTT and other terpenoids occurring in blends of herbivore-infested lima bean activate defense gene expression in naïve plants of the same species (Arimura et al. 2000).

Induction of TMTT synthesis after inoculation with ES4326 avrRpm1 is controlled through JA-mediated signaling pathways but is independent of plant SA production and SA-associated defense signaling (Fig. 3). The severely compromised synthesis of TMTT in JA biosynthesis mutants suggests that accumulation of JA is necessary for the production of the homoterpene in the incompatible Arabidopsis-P. syringae interaction. A low induction of TMTT in the opr3 mutant, which is able to form the JA biosynthetic precursor OPDA but not JA, also indicates a certain signaling competency for OPDA for TMTT synthesis (Fig. 3A). OPDA and JA are both produced to substantial levels in leaves inoculated with avirulent $P$. syringae (Grun et al. 2007; Zeier et al. 2004), and their pathogen-induced accumulation is thus likely to trigger TMTT production. However, in response to infection with low or medium titers of the compatible ES4326 strain (e.g., optical density $(\mathrm{OD})=0.005$ used in this study to trigger volatile emission), increases in leaf JA levels are much less pronounced than in response to avirulent ES4326 avrRpm1. In fact, JA levels do not rise significantly
B

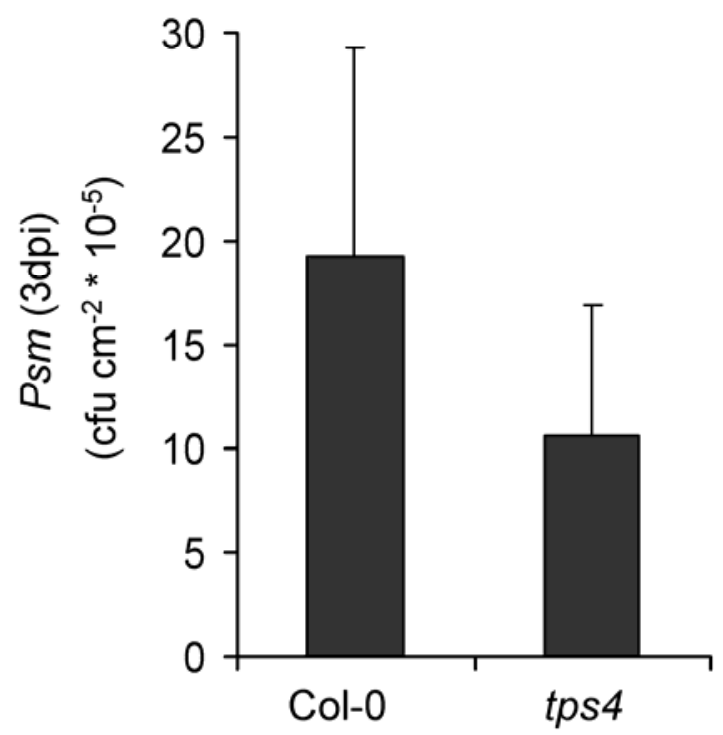

Fig. 6. Specific and basal disease resistance of wild-type Col-0 and tps 4 mutant plants. Bacterial growth quantification of A, P. syringae pv. maculicola avrRpm1 (optical density [OD] =0.005)- and B, P. syringae pv. maculicola $($ Psm $)(\mathrm{OD}=0.001)$-inoculated leaves of wild-type and tps4 mutants 3 days after inoculation. Bars represent mean values ( \pm standard deviation) of CFU per square centimeter from at least five parallel samples, each sample consisting of three leaf disks. Asterisk denotes tps 4 value with statistically significant differences to the wild-type value $(P<0.05$; Student's $t$-test). To ensure the uniformity of infiltrations, initial bacterial numbers ( $1 \mathrm{~h}$ postinoculation [hpi]) were quantified. No significant differences in bacterial numbers were detected at 1 hpi for leaves of different lines (data not shown). 
until day 2 after ES4326 inoculation (Mishina et al. in press). This almost excludes a signaling function of JA for TMTT production in the compatible interaction. Here, the phytotoxin and JA mimic coronatine, which is produced by several $P$. syringae pathovars, including ES4326 (Bender et al. 1996), might represent the predominant trigger for TMTT production. Signaling pathways that contribute to control of $P$. syringaeelicited TMTT synthesis downstream of JA or coronatine include both the jasmonate-amino acid synthetase JAR1 and the
MYC transcription factor JIN1. The signaling events underlying microbial induction of TMTT synthesis in Arabidopsis are similar but not identical to those of herbivore-induced homoterpene synthesis in other species. For instance, induced TMTT production in tomato depends on functional JA biosynthesis. However, unlike wild-type, SA-deficient NahG tomato plants are blocked in TMTT synthesis upon spider mite herbivory, suggesting a requirement of SA signaling (Ament et al. 2006). The octadecanoid pathway also controls TMTT synthesis in
A

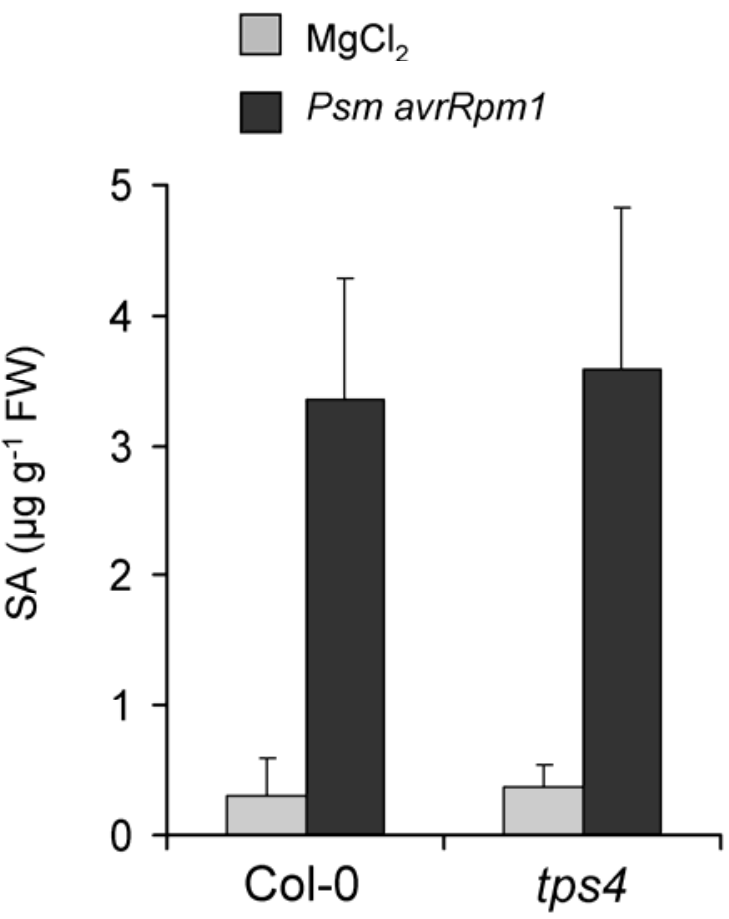

C

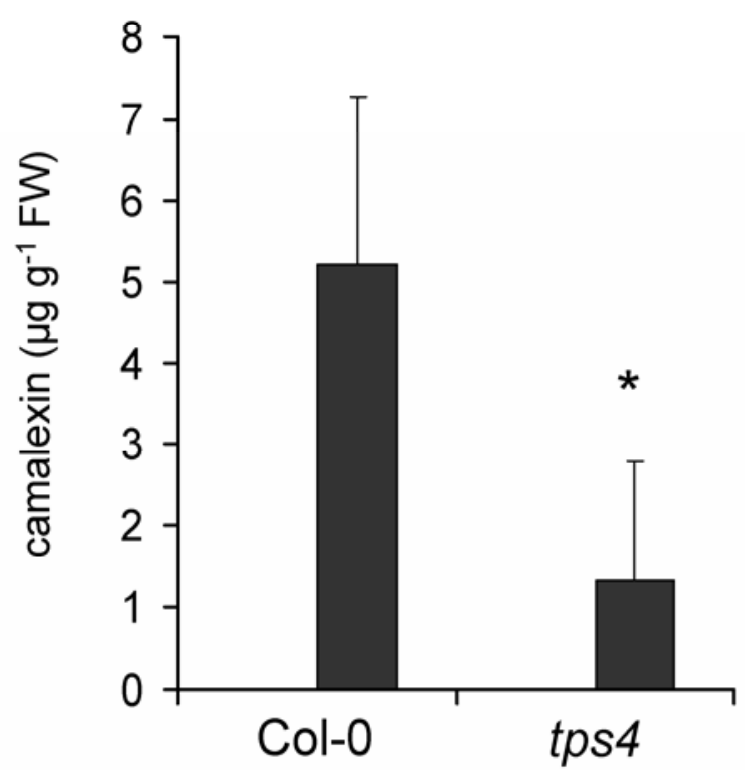

B

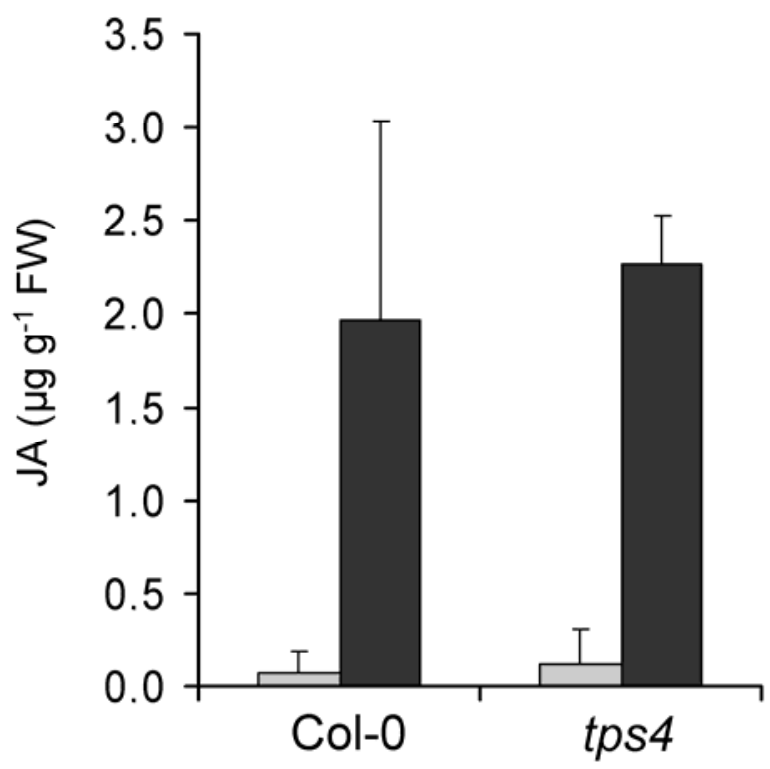

D

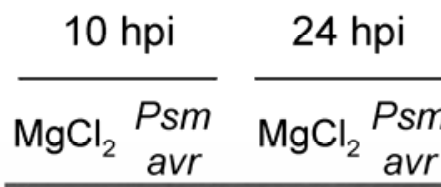

Col-0
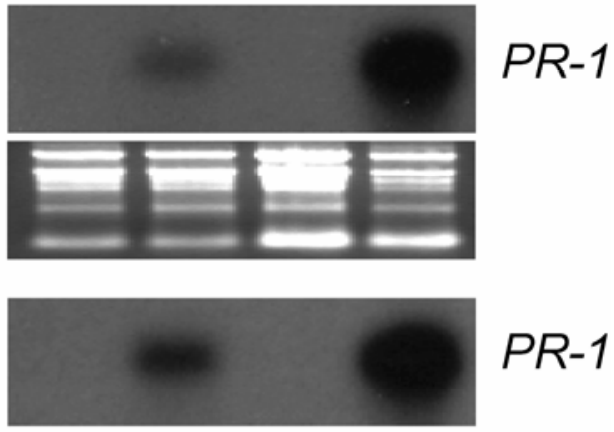

$P R-1$

Fig. 7. Defense responses in leaves of wild-type Col-0 and tps4 mutant plants at sites of Pseudomonas syringae pv. maculicola avrRpm1 (optical density = 0.005) inoculation. Control samples were treated with $10 \mathrm{mM} \mathrm{MgCl}_{2}$. A, Salicylic acid (SA) levels at $10 \mathrm{~h}$ postinoculation [hpi]. B, Jasmonic acid (JA) levels at 10 hpi. C, Camalexin accumulation at 10 hpi (camalexin was not detected in control leaves). In $\mathbf{A}$ through $\mathbf{C}$, bars represent mean values ( \pm standard deviation) of three independent samples, each sample consisting of six leaves from two different plants. The asterisk denotes tps 4 value with statistically significant difference to the respective wild-type value $\left(P<0.05\right.$; Student's $t$-test). Light bars indicate: $\mathrm{MgCl}_{2}$-treatment and dark bars $P$. syringae pv. maculicola avrRpml inoculation. D, Expression of the defense gene $P R-1$, assessed by Northern blot analysis. Control samples were infiltrated with $10 \mathrm{mM} \mathrm{MgCl}_{2}$. Leaf samples were taken at 10 and $24 \mathrm{hpi}$. 
lima bean. Here, exogenous treatment of leaves with the JA precursors linolenic acid and OPDA but not JA itself provoke TMTT emission (Koch et al. 1999). In Medicago truncatula, herbivore-induced emission of TMTT and other terpenoids is mediated by a concerted action of JA, ethylene, and calcium signaling (Arimura et al. 2008).

We have detected a remarkable similarity between metabolic changes occurring after $P$. syringae inoculation and $\mathrm{CuSO}_{4}$
A

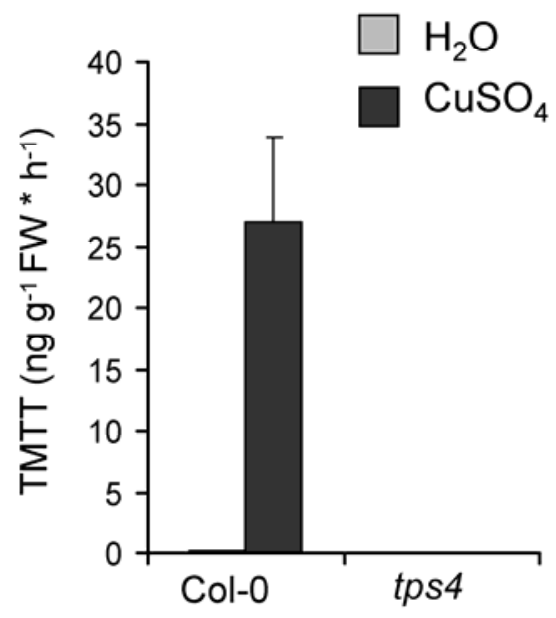

D

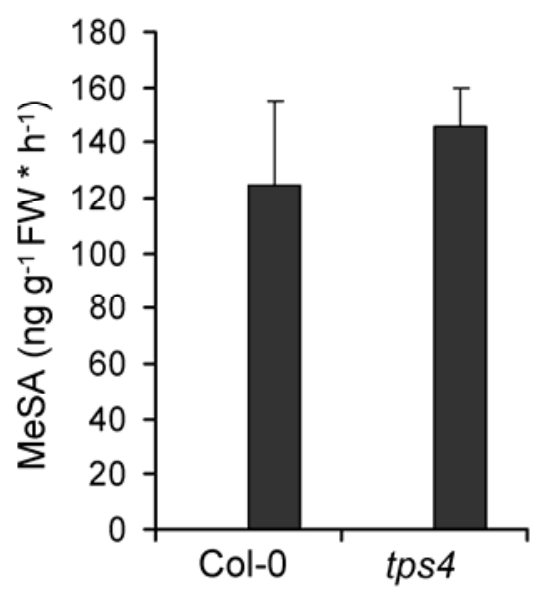

G

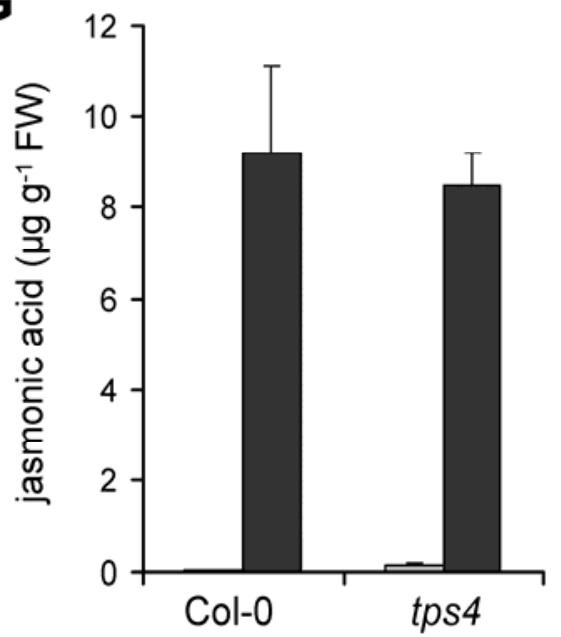

B

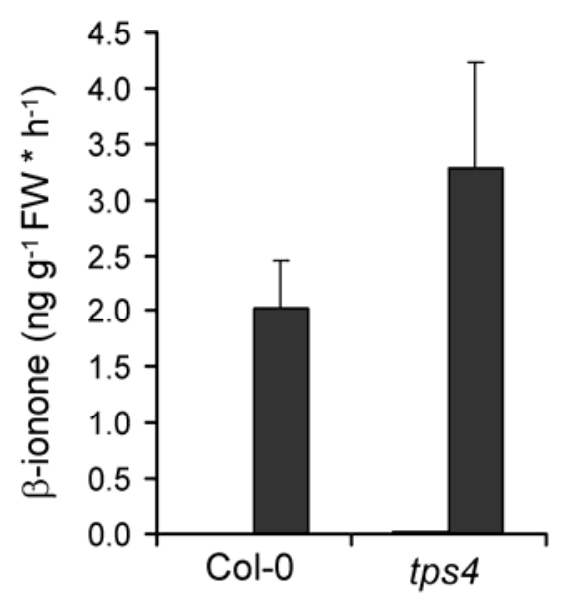

$\mathbf{E}$

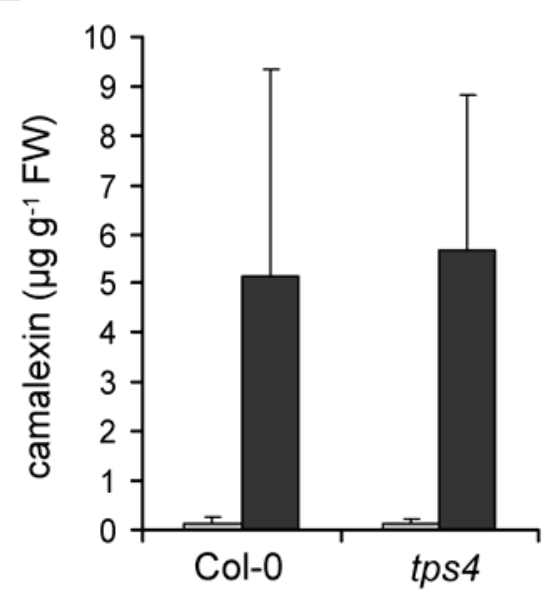

C

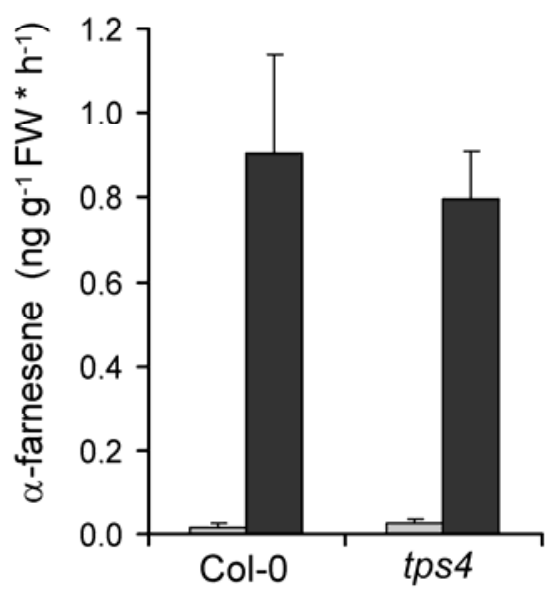

$\mathbf{F}$

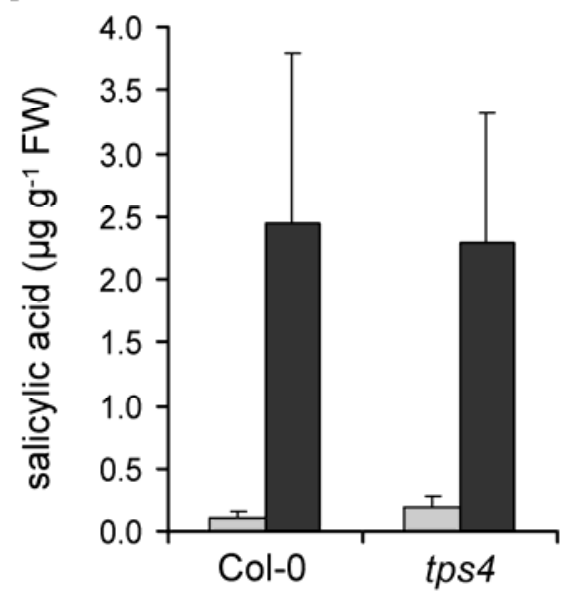

Fig. 8. Induction of leaf volatile organic compounds emission and defense metabolite production upon $\mathrm{CuSO}_{4}$ stress in wild-type Col-0 and tps 4 mutant plants. A through $\mathbf{D}$, Leaf volatiles were collected for $48 \mathrm{~h}$ after infiltration with $10 \mathrm{mM} \mathrm{CuSO}_{4}$ or after infiltration with water as a control treatment. Values are given in nanograms of volatile substance per gram of fresh weight (FW) per h. A, E,E)-4,8,12-trimethyl-1,3,7,11-tridecatetraene (TMTT) emission, B, $\beta$ ionone emission, $\mathbf{C}$, $\alpha$-farnesene emission, and $\mathbf{D}$, methyl salicylate emission. $\mathbf{E}$ through $\mathbf{G}$, Leaf metabolite levels were determined at 48 h posttreatment and are given in micrograms of substance per gram of FW. E, Camalexin levels, F, salicylic acid levels, and $\mathbf{G}$, jasmonic acid levels. Bars represent mean values ( \pm standard deviation) of at least five independent samples. Light bars indicate water infiltration and dark bars infiltration with $10 \mathrm{mM} \mathrm{CuSO}_{4}$. 
treatment, which involves induced synthesis of the volatiles TMTT, MeSA, $\beta$-ionone, and $\alpha$-farnesene, as well as increased production of the nonvolatile defense metabolites camalexin, SA, and JA (Fig. 8). At the transcriptional level, such overlapping responses between pathogen-infected and heavy metaltreated plants have been previously reported. For instance, many cytochrome P450 genes, some of which are known to participate in secondary metabolite biosynthesis, are upregulated in Arabidopsis by both Alternaria brassicicola inoculation and copper stress (Narusaka et al. 2004). Similar to P. syringae infection, copper excess leads to increased production of ROS and oxidative stress (Drazkiewicz et al. 2004; Grun et al. 2007). Through activation of expression of genes involved in secondary metabolite production, ROS-induced signaling might thus account for the metabolic changes observed by both treatments. With regard to plant VOC production, it would be interesting to examine whether ROS indeed function as upstream signals in the biosynthesis of terpenoid volatiles and MeSA in future experiments.
Of the four Arabidopsis TPS genes upregulated after $P$. syringae infection, TPS4 is most prominently expressed in both incompatible and compatible interactions. Moreover, like other defense reactions in Arabidopsis, such as synthesis of SA, accumulation of camalexin, and expression of PR genes, TPS4 expression is initiated earlier in response to avirulent than to virulent pathogens (Fig. 4). This difference is based on additional recognition events in incompatible interactions that are mediated by specific interaction of pathogen-derived avirulence proteins with plant resistance receptors (Nimchuk et al. 2003). The identified tps 4 knockout line completely fails to show both expression of TPS4 and induction of TMTT emission. This demonstrates that expression of functional TPS4 is required for TMTT biosynthesis (Figs. 4, 5, and 8). In planta conversion studies with ${ }^{2} \mathrm{H}$-labeled precursors strongly suggest that TMTT is synthesized via the diterpene precursor (E,E)geranyllinalool, which is produced from geranylgeranyl diphosphate (Boland and Gäbler 1989). As a member of the TPS family, TPS4 has been previously suggested to catalyze this
A

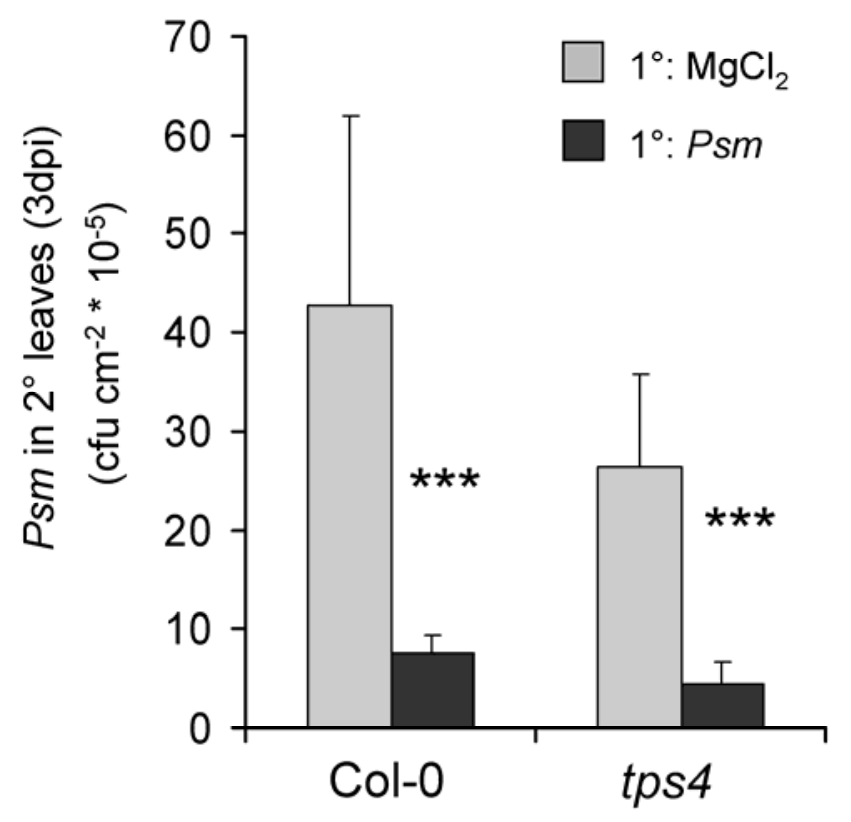

C

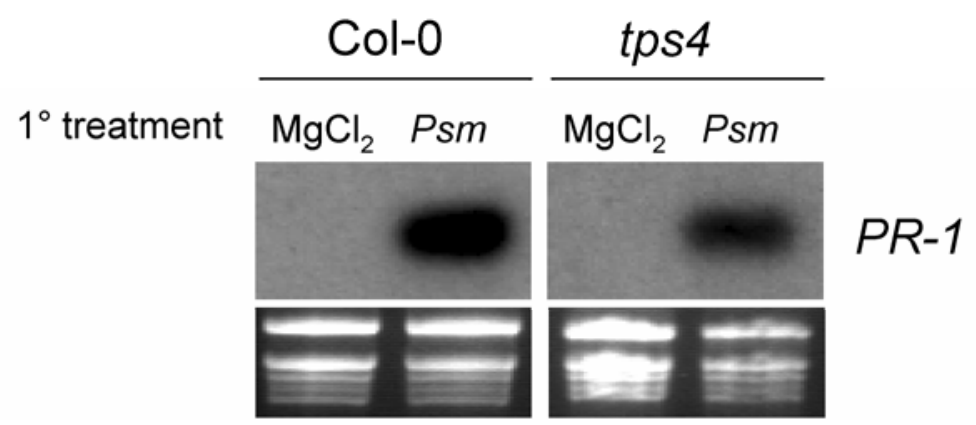

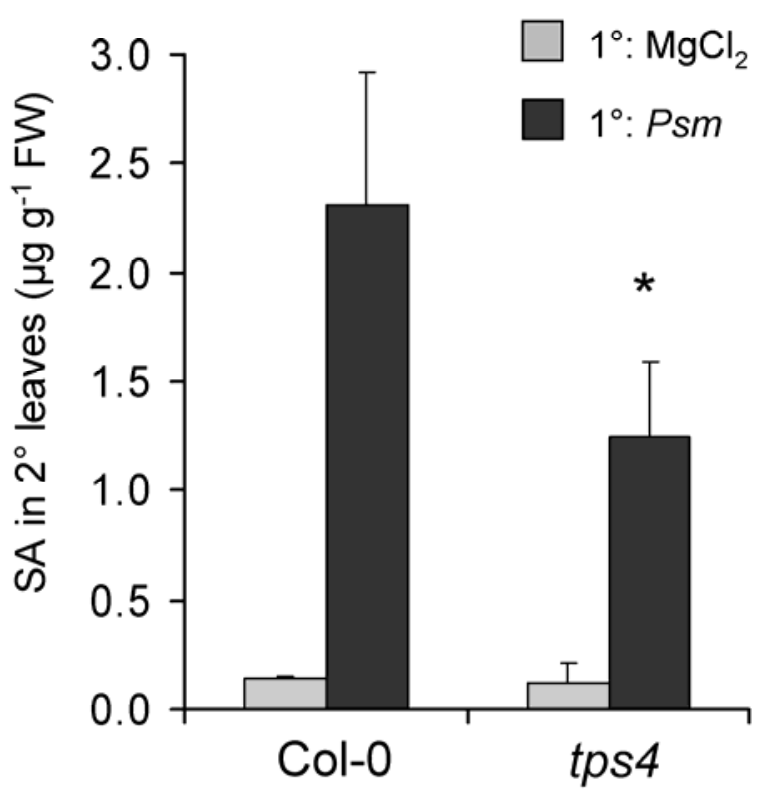

Fig. 9. Systemic defenses in wild-type Col-0 and tps4 mutant plants. A, Bacterial growth quantification to directly assess systemic acquired resistance (SAR). Plants were pretreated with either $10 \mathrm{mM} \mathrm{MgCl}$ or Pseudomonas syringae pv. maculicola (Psm) (optical density [OD] $=0.01$ ) in three primary leaves $\left(1^{\circ}\right.$ treatment), and 2 days later, three systemic $\left(2^{\circ}\right)$ leaves located directly above the primary leaves were inoculated with $P$. syringae pv. maculicola $(\mathrm{OD}=0.001)$. Bacterial growth in systemic leaves was assessed 3 days after the $2^{\circ}$ inoculation. Bars represent mean values ( \pm standard deviation) of $C F U$ per square centimeter from at least seven parallel samples, each consisting of three leaf disks. Asterisks denote statistically significant differences in growth between plants of a particular line pretreated with $P$. syringae pv. maculicola or $\mathrm{MgCl}_{2}(P<0.001$; Student's $t$-test). B and $\mathbf{C}$, Accumulation of salicylic acid (SA) and induction of $P R-1$ expression in untreated $2^{\circ}$ leaves. Treatments of $1^{\circ}$ leaves were performed as described for A. The $2^{\circ}$ leaves were harvested for analyses 2 days later. B, Systemic SA accumulation. Bars represent mean values ( \pm standard deviation) of three independent samples, each sample consisting of six leaves from two different plants. The asterisk denotes statistically significant differences between SAR-induced Col- 0 and $t p s 4$ plants $(P<0.05$; Student's $t$ test). Light bars indicate $1^{\circ} \mathrm{MgCl}_{2}$-treatment and dark bars $1^{\circ}$ P. syringae pv. maculicola inoculation. $\mathbf{C}$, Systemic expression of $P R-1$. 
latter conversion (Aubourg et al. 2002). During the preparation of our manuscript, Herde and associates (2008) have confirmed TPS4 to act as a geranyllinalool synthase by biochemical characterization of the recombinant protein and analyses TMTTdeficient phenotypes of two independent T-DNA insertion lines, Salk_078187 (used in the current study) and Salk_039864. TPS4 thus catalyzes a first step in the formation of TMTT. The $\mathrm{C}_{20}$ carbon chain of geranyllinalool is supposed to be subsequently shortened by other enzymes, e.g., by cytochrome P450 monooxygenases (Dudareva et al. 2004), to yield the $\mathrm{C}_{16}$-compound TMTT.

The wild type-like emission profiles from TPS10 knockout mutants indicate that TPS10 is neither involved in TMTT production (Fig. 5C) nor in biosynthesis of $\beta$-ionone nor $\alpha$-farnesene (data not shown). When functionally expressed in Escherichia coli, TPS10 converts geranyl diphosphate into the acyclic monoterpenes $\beta$-myrcene and (E)- $\beta$-ocimene (Bohlmann et al. 2000). Although TPS10 is upregulated by $P$. syringae (Fig. 4A), we were unable to detect these monoterpenes in the volatile blend of ES4326 ( \pm avrRpm1)-infected Arabidopsis.

The tps 4 mutant exhibits a growth phenotype indistinguishable from wild type, and except for TMTT production, volatile blends of tps 4 and Col-0 plants are identical. Comparative examination of resistance responses in Col-0 and tps 4 thus allowed us to functionally characterize the relevance of induced TMTT production in disease resistance against microbial pathogens. To our knowledge, this is the first study in which the role of in planta-produced terpenoids in pathogen defense has been directly assessed on a genetic basis.

If at all, untreated Arabidopsis plants only produce traces of TMTT, and a substantial emission only occurs after pathogen contact. This accumulation pattern is a characteristic feature of phytoalexins. Phytoalexins are defined as relatively lipophilic low-molecular weight compounds that are produced after contact with microbial pathogens and exhibit antimicrobial activity against fungi or bacteria (Kuć 1995). Because many terpenoids possess antimicrobial properties (Soković and Griensven 2006), we considered the possibility that TMTT might act as an Arabidopsis phytoalexin. Sesqui- and diterpenoid phytoalexins exist in several plant species, including tomato, sweet pepper, potato, cotton, and rice (Brooks and Watson 1991). Our bacterial growth data indicate, however, that tps 4 is at least as resistant to avirulent and virulent ES4326 as Col-0 (Fig. 6), which essentially excludes a function for TMTT as a phytoalexin that is effective against $P$. syringae. TMTT might either have no or insufficient bactericidal activity or the apoplast-colonizing bacteria do not come in contact with sufficient amounts of homoterpene vapors. On a fresh-weight base, P. syringae-induced TMTT emission from Arabidopsis plants is relatively low (10 to $20 \mathrm{ng}$ per gram of fresh weight per h) compared with many other plants. It falls, for example, at least one order of magnitude below the levels of the main terpenoid emitted from herbivore-infested soybean plants (Rostás and Eggert 2008). Alternatively, ES4326 might have evolved strategies to tolerate a potential antimicrobial action of TMTT.

Exogenous application of the monoterpene allo-ocimene primes Arabidopsis defense reactions against the fungal pathogen Botrytis cinerea (Kishimoto et al. 2006). In a comparable way, TMTT produced upon $P$. syringae inoculation might positively or negatively influence other inducible defense responses. We have shown that tps 4 is not compromised in the production of SA and JA in inoculated leaves, and that $P R-1$ expression in the mutant occurs in a wild type-like manner. This indicates that major inducible defense reactions towards $P$. syringae are not primed or otherwise influenced by TMTT in wild-type plants. This statement also holds true for camalexin production, although significantly lower levels of camalexin accumulated upon $P$. syringae challenge in tps 4 than in wildtype leaves. The latter finding can be ascribed to the reduced bacterial multiplication in tps 4 , resulting in attenuated elicitation of camalexin synthesis. $\mathrm{CuSO}_{4}$ intoxication as a more robust abiotic stimulus, by contrast, entailed a wild type-like production of camalexin in tps 4 .

We can also exclude an essential function for TMTT during establishment of SAR, because bacterial-growth assays indicated that tps 4 is able to mount $P$. syringae-induced SAR as effectively as Col-0. The modest reduction of systemic SA and $P R-1$ accumulation in tps 4 compared with Col-0 might be cautiously interpreted to mean that TMTT contributes to the realization of systemic defense responses (Fig. 9). However, a scenario in which TMTT emission from lower leaves would prime upper leaves for SAR responses is unrealistic because of the clear SAR response observed in tps4. The other major Arabidopsis volatile produced after $P$. syringae attack, MeSA, has been recently identified as a critical SAR long-distance signal in tobacco (Park et al. 2007). Whether methyl salicylate is a general SAR signal in Arabidopsis and other species has not yet been established.

In summary, we can state that although TMTT synthesis is markedly activated in Arabidopsis upon P. syringae inoculation, the significance of this response for defense and resistance against the bacterial pathogen is rather low. This is reminiscent of camalexin accumulation which is produced during the first $24 \mathrm{~h}$ of the Arabidopsis-P. syringae interaction at levels exceeding those of TMTT (approximately 0.25 to $0.5 \mu \mathrm{g}$ per gram of fresh weight) by one to two orders of magnitude (Mishina and Zeier 2007b). Like TMTT, camalexin is dispensable for resistance against $P$. syringae, as it is for effective defense towards other pathogens with a biotrophic lifestyle (Zhou et al. 1999). Considering the fact that pathogens are recognized in a highly specific manner by plant resistance receptors (Nimchuk et al. 2003), it is surprising that, instead of specifically activating responses that efficiently help to restrict invasion of the particular intruder, plants rather invest nonspecifically in an array of defenses that includes a number of ineffective responses. In other words, a high recognition specificity is followed by a nonspecific, luxurious defense outcome. Our study supports a previously formulated hypothesis that plants can form VOC as byproducts of other processes and, due to their volatility, are emitted to the atmosphere with no apparent function (Holopainen 2004). Activation of JA signaling after microbial infection, herbivore feeding, and heavy-metal stress seems to entail TMTT production in a self-acting manner, regardless of whether or not it is biologically meaningful.

\section{MATERIALS AND METHODS}

\section{Plant material and growth conditions.}

Arabidopsis thaliana (L.) Heynh. plants were grown on an autoclaved mixture of soil (Klasmann, Beetpfanzensubstrat Typ R.H.P.16), vermiculite, and sand (10:0.5:0.5). Plants were cultivated in a controlled environmental chamber (J-66LQ4; Percival, Boone, IA, U.S.A.) with a 9-h day (photon flux density $70 \mu \mathrm{mol} \mathrm{m} \mathrm{m}^{-2} \mathrm{~s}^{-1}$ ) and $15-\mathrm{h}$ night cycle and a relative humidity of $70 \%$. Growth temperatures were set to $21^{\circ} \mathrm{C}$ during the day period and to $18^{\circ} \mathrm{C}$ during the night. Naïve and unstressed 6week-old plants showing a uniform appearance were used for experiments.

The tps 4 mutant line represents the Salk T-DNA insertion line SALK_078187, and tps 10-1 and tps10-2 mutants originate from lines SALK_108420 and SALK_041114, respectively. All Arabidopsis insertion lines are in the Col-0 background. Homozygous insertion mutants were identified by PCR, using gene-specific (TPS4-forward: 5'-GCGTACGACAAGTATTTG 
CAG-3', TPS4-reverse: 5'-AAGTTCACGGCC-TAATGCTTC3', TPS10-1-forward: 5'-CATGGAAACTTGCATGT-GTTG3', TPS10-1-reverse: 5'-TTTGTTCATGCATATATACCAGCT C-3', TPS10-2-forward: 5'-AATTCAA-CGACGACAAGGTTC3', TPS10-2-reverse: 5'-TTCAATATGGC-CACTCTCCTG-3') and T-DNA-specific primers according to Alonso and associates (2003). The examined JA pathway mutants dde2-2 (von Malek et al. 2002), opr3 (Stintzi and Browse 2000), and jin1 (Berger et al. 1996) have Col-0, Ws, and Col-3 backgrounds, respectively. All other defense mutants used in the present study are described in Mishina and Zeier (2007b).

\section{Cultivation of bacteria.}

ES4326 lacking or carrying the avrRpml avirulence gene were grown in King's B medium containing the appropriate antibiotics at $28^{\circ} \mathrm{C}$ (Zeier et al. 2004). Overnight log phase cultures were washed three times with $10 \mathrm{mM} \mathrm{MgCl}_{2}$ and were diluted to different final OD for leaf inoculations.

\section{Collection of volatiles.}

To assess $P$. syringae-induced plant volatile emission, bacterial suspensions at OD 0.01 were infiltrated from the abaxial side into seven full-grown rosette leaves per Arabidopsis plant, using a $1-\mathrm{ml}$ syringe without a needle. Control treatments were performed by infiltrating a $10-\mathrm{mM} \mathrm{MgCl}_{2}$ solution. For copper sulfate treatments, leaves were infiltrated with a solution of 10 $\mathrm{mM} \mathrm{CuSO}_{4}$.

Volatiles emitted by individual plants were collected in a push-pull apparatus essentially as described by Rostás and associates (2006). The system consisted of six independent circular glass chambers $(13 \mathrm{~cm}$ in diameter, $12 \mathrm{~cm}$ in height $)$ that allowed for simultaneous collection. Plants were placed in chambers about 30 min after leaf infiltrations, and trapping filters consisting of glass tubes packed with Super-Q absorbent (VCT-1/4X3-SPQ, Analytical Research Systems, Gainsville, FL, U.S.A.) were attached in a way so that the tip of each filter were a distance of $1 \mathrm{~cm}$ from each plant rosette. Charcoalfiltered and humidified air was pushed into each sampling chamber at a rate of 1.2 liters per min. The air flow containing plant volatiles was pulled through the trapping filter with a vacuum pump (ME2; Vacuubrand, Wertheim, Germany). After collecting volatiles for 10 to $24 \mathrm{~h}$, trapping filters were removed, extracted, and analyzed as described below.

\section{Chemical analysis of volatile extracts.}

Trapping filters were eluted with $1 \mathrm{ml} \mathrm{CH}_{2} \mathrm{Cl}_{2}$ after each collection, and $200 \mathrm{ng}$ of n-octane was added as internal standard. The mixture was concentrated to a volume of $25 \mu$ l under a gentle stream of nitrogen, strictly avoiding evaporation to dryness, and was analyzed by gas chromatography-mass spectrometry. Three-microliter aliquots of the sample mixture were separated on a gas chromatograph $(6890 \mathrm{~N}$; Agilent Technologies, Waldbronn, Germany) that was equipped with a splitsplitless injector and a fused silica capillary column (HP-1; 30 $\mathrm{m} \times 0.25 \mathrm{~mm}$ ID, $0.25-\mu \mathrm{m}$ film thickness) and were combined with a 5975 mass spectrometric detector (Agilent Technologies). Samples were injected in pulsed splitless mode, and helium was used as a carrier gas. The temperature of the oven was held at $50^{\circ} \mathrm{C}$ for $2 \mathrm{~min}$ and then was increased at $8^{\circ} \mathrm{C}$ per min to $300^{\circ} \mathrm{C}$. Mass spectra were recorded at $70 \mathrm{eV}$. Substances were identified by comparison of mass spectra with those from the NIST 98 reference library. Compound identities were confirmed by comparison of mass spectra and retention times with those of standard substances. To allow sensitive quantification of volatiles, substance peaks originating from selected ion chromatograms were integrated (generally $\mathrm{m} / \mathrm{z} 81$ for TMTT and $\alpha$-farnesene, m/z 177 for $\beta$-ionone, m/z 120 for MeSA).
The resulting peak areas were related to the peak area of the n-octane standard (ion chromatogram $\mathrm{m} / \mathrm{z} 114$ ), whereby appropriate correction factors were considered for each substance.

\section{Characterization of local and systemic resistance responses.}

For the determination of local defense responses, bacterial suspensions at OD 0.005 (determination of gene expression, metabolite levels, ES4326 avrRpm1 growth assay) or OD 0.001 (ES4326 growth assays) were infiltrated into three full-grown leaves per plant. Bacterial growth was assessed 3 days after infiltration by homogenizing disks originated from infiltrated areas of three different leaves in $1 \mathrm{ml}$ of $10 \mathrm{mM} \mathrm{MgCl}_{2}$, plating appropriate dilutions on King's B medium, and counting colony numbers after incubating the plates at $28^{\circ} \mathrm{C}$ for 2 days.

For SAR experiments, plants were first infiltrated into three lower $\left(1^{\circ}\right)$ leaves with a suspension of ES4326 $(\mathrm{OD}=0.01)$ or with $10 \mathrm{mM} \mathrm{MgCl}_{2}$ as a control treatment. Two days after the primary treatment, upper $\left(2^{\circ}\right)$ leaves were either harvested for SA determination and gene expression analysis or were inoculated with virulent ES4326 (OD 0.001). Growth of ES4326 in $2^{\circ}$ leaves was scored another 3 days later.

\section{Determination of leaf SA, JA, and camalexin levels.}

Determination of SA, JA, and camalexin levels in leaves was realized by vapor-phase extraction and subsequent gas chromatography-mass spectrometry analysis according to Mishina and Zeier (2006).

\section{Analysis of gene expression.}

Expression levels of PR-1 (At2g14610) and TPS4 (At1g61120) were determined by Northern blot analysis as described by Mishina and Zeier (2006).

\section{ACKNOWLEDGMENTS}

We thank T. Turlings and M. Held for providing TMTT standard, and S. Berger for donation of Arabidopsis dde2, opr3, and jin1 mutant seeds. Financial support from the Deutsche Forschungsgemeinschaft (Graduiertenkolleg 1342) is gratefully acknowledged. E. Attaran is a Deutscher Akademischer Austauschdienst fellow.

\section{LITERATURE CITED}

Aharoni, A., Giri, A. P., Deuerlein, S., Griepink, F., de Kogel, W. J., Verstappen, F. W., Verhoeven, H. A., Jongsma, M. A., Schwab, W., and Bouwmeester, H. J. 2003. Terpenoid metabolism in wild-type and transgenic Arabidopsis plants. Plant Cell 15:2866-2884.

Alonso, J. M., Stepanova, A. N., Leisse, T. J., Kim, C. J., Chen, H., Shinn, P., Stevenson, D. K., Zimmerman, J., Barajas, P., Cheuk, R., Gadrinab, C., Heller, C., Jeske, A., Koesema, E., Meyers, C. C., Parker, H., Prednis, L., Ansari, Y., Choy, N., Deen, H., Geralt, M., Hazari, N., Hom, E., Karnes, M., Mulholland, C., Ndubaku, R., Schmidt, I., Guzman, P., Aguilar-Henonin, L., Schmid, M., Weigel, D., Carter, D. E., Marchand, T., Risseeuw, E., Brogden, D., Zeko, A., Crosby, W. L., Berry, C. C., and Ecker. J. R. 2003. Genome-wide Insertional mutagenesis of Arabidopsis thaliana. Science 301:653-657.

Ament, K., Kant, M. R., Sabelis, M. W., Haring, M. A., and Schuurink, R. C. 2004. Jasmonic acid is a key regulator of spider mite-induced volatile terpenoid and methyl salicylate emission in tomato. Plant Physiol. 135:2025-2037.

Ament, K., Van Schie, C. C., Bouwmeester, H. J., Haring, M. A., and Schuurink, R. C. 2006. Induction of a leaf specific geranylgeranyl pyrophosphate synthase and emission of (E,E)-4,8,12-trimethyltrideca1,3,7,11-tetraene in tomato are dependent on both jasmonic acid and salicylic acid signaling pathways. Planta 224:1197-1208.

Arimura, G., Ozawa, R., Shimoda, T., Nishioka, T., Boland, W., and Takabayashi, J. 2000. Herbivory-induced volatiles elicit defence genes in lima bean leaves. Nature 406:512-515.

Arimura, G., Garms, S., Maffei, M., Bossi, S., Schulze, B., Leitner, M., Mithöfer, A., and Boland, W. 2008. Herbivore-induced terpenoid emission in Medicago truncatula: Concerted action of jasmonate, ethylene and calcium signaling. Planta 227:453-464. 
Aubourg, S., Lecharny, A., and Bohlmann, J. 2002. Genomic analysis of the terpenoid synthase (AtTPS) gene family of Arabidopsis thaliana. Mol. Genet. Genomics 267:730-745.

Barth, C., and Jander, G. 2006. Arabidopsis myrosinases TGG1 and TGG2 have redundant function in glucosinolate breakdown and insect defense. Plant J. 46:549-562.

Bender, C. L., Palmer, D., Peñaloza-Vázquez, A., Rangaswamy, V., and Ullrich, M. 1996. Biosynthesis of coronatine, a thermoregulated phytotoxin produced by the phytopathogen Pseudomonas syringae. Arch. Microbiol. 166:71-75.

Berger, S., Bell, E., and Mullet, J. E. 1996. Two methyl jasmonate-insensitive mutants show altered expression of atvsp in response to methyl jasmonate and wounding. Plant Physiol. 111:525-531.

Bohlmann, J., Martin, D., Oldham, N. J., and Gershenzon, J. 2000 Terpenoid secondary metabolism in Arabidopsis thaliana: cDNA cloning, characterization, and functional expression of a myrcene/(E)- $\beta$-ocimene synthase. Arch. Biochem. Biophys. 375:261-269.

Boland, W., and Gäbler, A. 1989. Biosynthesis of homoterpenes in higher plants. Helv. Chim. Acta 72:247-253.

Brooks, C. J. W., and Watson, D. G. 1991. Terpenoid phytoalexins. Nat. Prod. Rep. 8:367-389.

Cao, H., Bowling, S. A., Gordon, A. S., and Dong, X. 1994. Characterization of an Arabidopsis mutant that is nonresponsive to inducers of systemic acquired resistance. Plant Cell 6:1583-1592.

Century, K. S., Holub, E. B., and Staskawicz, B. J. 1995. NDR1, a locus of Arabidopsis thaliana that is required for disease resistance to both a bacterial and a fungal pathogen. Proc. Natl. Acad. Sci. U.S.A. 92:65976601

Conrath, U., Pieterse, C. M. J., and Mauch-Mani, B. 2002. Priming in plant-pathogen interactions. Trends Plant Sci. 7:210-216.

Croft, K., Juttner, F., and Slusarenko, A. J. 1993. Volatile products of the lipoxygenase pathway evolved from Phaseolus vulgaris (L.) leaves inoculated with Pseudomonas syringae pv phaseolicola. Plant Physiol. 101:13-24.

Dangl, J. L., and Jones, J. D. G. 2001. Plant pathogens and integrated defence responses to infection. Nature 411:826-833.

De Boer, J. G., Posthumus, M. A., and Dicke, M. 2004. Identification of volatiles that are used in discrimination between plants infested with prey or nonprey herbivores by a predatory mite. J. Chem. Ecol. 30:2215-2230.

Delledonne, M., Xia, Y., Dixon, R. A., and Lamb, C. 1998. Nitric oxide functions as a signal in plant disease resistance. Nature 394:585-588.

Drazkiewicz, M., Skorzynska-Polit, E., and Krupa, Z. 2004. Copper-induced oxidative stress and antioxidant defence in Arabidopsis thaliana. Biometals 17:379-387.

Duan, H., Huang, M. Y., Palaci,. K., and Schuler, M. A. 2005. Variations in CYP74B2 (hydroperoxide lyase) gene expression differentially affect hexenal signaling in the Columbia and Landsberg erecta ecotypes of Arabidopsis. Plant Physiol. 139:1529-1544.

Dudareva, N., Pichersky, E., and Gershenzon J. 2004. Biochemistry of plant volatiles. Plant Physiol. 135:1893-1902.

Durrant, W. E., and Dong, X. 2004. Systemic acquired resistance. Annu. Rev. Phytopathol. 42:185-209

Engelberth, J., Alborn, H. T., Schmelz, E. A., and Tumlinson, J. H. 2004 Airborne signals prime plants against insect herbivore attack. Proc. Natl. Acad. Sci. U.S.A 101:1781-1785.

Farmer, E. E., Alméras, E., and Krishnamurthy, V. 2003. Jasmonates and related oxylipins in plant responses to pathogenesis and herbivory. Curr. Opin. Plant Biol. 6:372-378.

Glawischnig, E. 2007. Camalexin. Phytochemistry 68:401-406.

Glazebrook, J., Zook, M., Mert, F., Kagan, I., Rogers, E. E., Crute, I. R., Holub, E. B, Hammerschmidt, R., and Ausubel, F. M. 1997. Phytoalexin-deficient mutants of Arabidopsis reveal that PAD4 encodes a regulatory factor and that four $P A D$ genes contribute to downy mildew resistance. Genetics 146:381-392.

Glazebrook, J. 2005. Contrasting mechanisms of defence against biotrophic and necrotrophic pathogens. Annu. Rev. Phytopathol. 43:205-227.

Grun, G., Berger, S., Matthes, D., and Mueller, M. J. 2007. Early accumulation of non-enymatically synthesized oxylipins in Arabidopsis thaliana after infection with Pseudomonas syringae. Funct. Plant Biol. 34:65-71.

Halim, V. A., Vess, A., Scheel, D., and Rosahl, S. 2006. The role of salicylic acid and jasmonic acid in pathogen defense. Plant Biol. (Stuttg). 8:307-313.

Herde, M., Gärtner, K., Köllner, T. G., Fode, B., Boland, W., Gershenzon, J., Gatz, C., and Tholl, D. 2008. Identification and regulation of TPS04/GES, an Arabidopsis geranyllinalool synthase catalyzing the first step in the formation of the insect-induced volatile $\mathrm{C}_{16}$-homoterpene TMTT. Plant Cell 20:1152-1168.

Holopainen, J. K. 2004. Multiple functions of inducible plant volatiles. Trends Plant Sci. 9:529-533.
Hopke, J., Donath, J., Blechert, S., and Boland, W. 1994. Herbivore-induced volatiles: The emission of acyclic homoterpenes from leaves of Phaseolus lunatus and Zea mays can be triggered by a $\beta$-glucosidase and jasmonic acid. FEBS (Fed. Eur. Biochem. Soc.) Lett. 352:146-150.

Huang, J., Cardoza, Y. J., Schmelz, E. A., Raina, R., Engelberth, J., and Tumlinson, J. H. 2003. Differential volatile emissions and salicylic acid levels from tobacco plants in response to different strains of Pseudomonas syringae. Planta 217:767-775.

Kessler, A., and Baldwin, I. T. 2001. Defensive function of herbivore-induced plant volatile emissions in nature. Science 291:2141-2144.

Kishimoto, K., Matsui, K., Ozawa, R., and Takabayashi, J. 2006. Analysis of defensive responses activated by volatile allo-ocimene treatment in Arabidopsis thaliana. Phytochemistry 67:1520-1529.

Koch, T., Krumm, T., Jung, V., Engelberth, J., and Boland, W. 1999. Differential induction of plant volatile biosynthesis in the lima bean by early and late intermediates of the octadecanoid-signaling pathway. Plant Physiol. 121:153-162.

Koo, Y. J., Kim, M. A., Kim, E. H., Song, J. T., Jung, C., Moon, J. K., Kim, J. H, Seo, H. S, Song, S. I., Kim, J. K., Lee, J. S., Cheong, J. J., and Choi, Y. D. 2007. Overexpression of salicylic acid carboxyl methyltransferase reduces salicylic acid-mediated pathogen resistance in Arabidopsis thaliana. Plant Mol. Biol. 64:1-15.

Kuć, J. 1995. Phytoalexins, stress metabolism, and disease resistance in plants. Annu. Rev. Phytopathol. 33:275-297.

Lee, H. I., León, J., and Raskin, I. 1995. Biosynthesis and metabolism of salicylic acid. Proc. Natl. Acad. Sci. U.S.A. 92:4076-4079.

Lee, S., Sharm, Y., Lee, T. K., Chang, M., and Davis, K. R. 2001. Lignification induced by pseudomonads harboring avirulent genes on Arabidopsis. Mol. Cells 12:25-31.

Lorenzo, O., Chico, J. M., Sánchez-Serrano, J. J., and Solano, R. 2004. JASMONATE-INSENSITIVE1 encodes a MYC transcription factor essential to discriminate between different jasmonate-regulated defense responses in Arabidopsis. Plant Cell 16:1938-1950.

Mercke, P., Kappers, I. F., Verstappen, F. W., Vorst, O., Dicke, M., and Bouwmeester, H. J. 2004. Combined transcript and metabolite analysis reveals genes involved in spider mite induced volatile formation in cucumber plants. Plant Physiol. 135:2012-2024.

Métraux, J.-P. 2002. Recent breakthrough in the study of salicylic acid biosynthesis. Trends Plant Sci. 7:332-334

Mishina, T. E., and Zeier, J. 2006. The Arabidopsis flavin-dependent monooxygenase FMO1 is an essential component of biologically induced systemic acquired resistance. Plant Physiol. 141:1666-1675.

Mishina, T. E., and Zeier, J. 2007a. Interactions of Arabidopsis with nonadapted Pseudomonas syringae strains: Possible determinants of bacterial non-host resistance. Physiol. Plant 131:448-461

Mishina, T. E., and Zeier, J. 2007b Pathogen-associated molecular pattern recognition rather than development of tissue necrosis contributes to bacterial induction of systemic acquired resistance in Arabidopsis. Plant J. 50:500-513.

Mishina, T. E., Griebel, T., Geuecke, M., Attaran, E., and Zeier, J. New insights into the molecular events underlying systemic acquired resistance. In: Biology of Molecular Plant-Microbe Interactions. Vol 6. Proceedings of the 13th Symposium. International Society for Molecular Plant-Microbe Interactions. Sorrento, Italy. In press.

Mueller, S., Hilbert, B., Dueckershoff, S., Roitsch, T., Krischke, M., Mueller, M. J., and Berger, S. 2008. General detoxification and stress responses are mediated by oxidized lipids through TGA transcription factors in Arabidopsis. Plant Cell 20:495-497.

Narusaka, Y., Narusaka, M., Seki, M., Umezawa, T., Ishida, J., Nakajima, M., Enju, A., and Shinozaki, K. 2004. Crosstalk in the responses to abiotic and biotic stresses in Arabidopsis: Analysis of gene expression in cytochrome P450 gene superfamily by cDNA microarray. Plant Mol. Biol 55:327-342.

Nawrath, C., and Métraux, J.-P. 1999. Salicylic acid induction-deficient mutants of Arabidopsis express $P R-2$ and $P R-5$ and accumulate high levels of camalexin after pathogen inoculation. Plant Cell 11:1393-1404.

Nimchuk, Z., Eulgem, T., Holt, B. F., 3rd, and Dangl, J. L. 2003. Recognition and response in the plant immune system. Annu. Rev. Genet. 37:579-609.

Paré, P. W., and Tumlinson, J. H. 1997. De novo biosynthesis of volatiles induced by insect herbivory in cotton plants. Plant Physiol. 114:1161-1167.

Park, S. W., Kaimoyo, E., Kumar, D., Mosher, S., and Klessig, D. F. 2007. Methyl salicylate is a critical mobile signal for plant systemic acquired resistance. Science 318:113-116.

Parker, J. E., Holub, E. B., Frost, L. N., Falk, A., Gunn, N. D., and Daniels, M. J. 1996. Characterization of eds1, a mutation in Arabidopsis suppressing resistance to Peronospora parasitica specified by several different RPP genes. Plant Cell 8:2033-2046.

Pedras, M. S., and Adio, A. M. 2008. Phytoalexins and phytoanticipins from the wild crucifers Thellungiella halophila and Arabidopsis thaliana: 
Rapalexin A, wasalexins and camalexin. Phytochemistry 69:889-93.

Reymond, P., and Farmer, E. E. 1998. Jasmonate and salicylate as global signals for defense gene expression. Curr. Opin. Plant Biol. 1:404-411.

Rostás, M., Ton, J., Mauch-Mani, B., and Turlings, T. C. 2006. Fungal infection reduces herbivore-induced plant volatiles of maize but does not affect naïve parasitoids. J. Chem. Ecol. 32:1897-1909.

Rostás, M., and Eggert, K. 2008. Ontogenetic and spatio-temporal patterns of induced volatiles in Glycine max in the light of the optimal defence hypothesis. Chemoecology 18:29-38.

Shulaev, V., Silverman, P., and Raskin, I. 1997. Airborne signaling by methyl salicylate in plant pathogen resistance. Nature 385:718-721.

Soković, M., and Griensven, L. 2006. Antimicrobial activity of essential oils and their components against the three major pathogens of the cultivated button mushroom, Agaricus bisporus. Eur. J. Plant Pathol. 116:211-224.

Staswick, P. E., and Tiryaki, I. 2004. The oxylipin signal jasmonic acid is activated by an enzyme that conjugates it to isoleucine in Arabidopsis. Plant Cell 16:2117-2127.

Stintzi, A., and Browse, J. 2000. The Arabidopsis male-sterile mutant, opr3, lacks the 12-oxophytodienoic acid reductase required for jasmonate synthesis. Proc. Natl. Acad. Sci. U.S.A. 97:10625-10630.

Tholl, D. 2006. Terpene synthases and the regulation, diversity and biological roles of terpene metabolism. Curr. Opin. Plant Biol. 9:297-304.

Thomma, B. P., Nelissen, I., Eggermont, K., and Broekaert, W. F. 1999. Deficiency in phytoalexin production causes enhanced susceptibility of Arabidopsis thaliana to the fungus Alternaria brassicicola. Plant J. 19:163-171.

Turlings, T. C. J., Lengwiler, U. B., Bernasconi, M. L., and Wechsler, D. 1998. Timing of induced volatile emissions in maize seedlings. Planta 207:146-152.

Van Poecke, R. M. P., Posthumus, M. A., and Dicke, M. 2001. Herbivore- induced volatile production by Arabidopsis thaliana leads to attraction of the parasitoid Cotesia rubecula: Chemical, behavioral, and gene-expression analysis. J. Chem. Ecol. 27:1911-1928.

Van Poecke, R. M. P., and Dicke, M. 2004. Indirect defence of plants against herbivores: Using Arabidopsis thaliana as a model plant. Plant Biol. 6:387-401.

Von Malek, B., van der Graaff, E., Schneitz, K., and Keller, B. 2002. The Arabidopsis male-sterile mutant $d d e 2-2$ is defective in the ALLENE $O X I D E S Y N T H A S E$ gene encoding one of the key enzymes of the jasmonic acid biosynthesis pathway. Planta 216:187-192.

Wegener, R., Schulz, S., Meiners, T., Hadwich, K., and Hilker, M. 2001. Analysis of volatiles induced by oviposition of elm leaf beetle Xanthogaleruca luteola on Ulmus minor. J. Chem. Ecol. 27:499-515.

Wildermuth, M. C., Dewdney, J., Wu, G., and Ausubel, F. M. 2001. Isochorismate synthase is required to synthesize salicylic acid for plant defence. Nature 414:562-565.

Zeier, J., Pink, B., Mueller, M. J., and Berger, S. 2004. Light conditions influence specific defence responses in incompatible plant-pathogen interactions: Uncoupling systemic resistance from salicylic acid and PR-1 accumulation. Planta 219:673-683.

Zhou, N., Tootle, T. L., and Glazebrook, J. 1999. Arabidopsis PAD3, a gene required for camalexin biosynthesis, encodes a putative cytochrome P450 monooxygenase. Plant Cell 11:2419-2428.

\section{AUTHOR RECOMMENDED INTERNET RESOURCE}

Salk Institute Genomic Analysis Laboratory T-DNA express Arabidopsis gene mapping tool:

signal.salk.edu/cgi-bin/tdnaexpress 